BIS WORKING PAPERS

No. 65 - April 1999

\title{
HIGHER PROFITS AND LOWER CAPITAL PRICES: IS FACTOR ALLOCATION OPTIMAL?
}

by

P S Andersen, M Klau and E Yndgaard

BANK FOR INTERNATIONAL SETTLEMENTS

Monetary and Economic Department

Basle, Switzerland 
BIS Working Papers are written by members of the Monetary and Economic Department of the Bank for International Settlements, and from time to time by other economists, and are published by the Bank. The papers are on subjects of topical interest and are technical in character. The views expressed in them are those of their authors and not necessarily the views of the BIS.

Copies of publications are available from:

Bank for International Settlements

Information, Press \& Library Services

$\mathrm{CH}-4002$ Basle, Switzerland

Fax: +41 61 / 2809100 and +4161/2808100

This publication is available on the BIS website (www.bis.org).

(C) Bank for International Settlements 1999.

All rights reserved. Brief excerpts may be reproduced or translated provided the source is stated. 
BIS WORKING PAPERS

No. 65 - April 1999

\title{
HIGHER PROFITS AND LOWER CAPITAL PRICES: IS FACTOR ALLOCATION OPTIMAL?
}

\author{
by
}

P S Andersen, M Klau and E Yndgaard*

\begin{abstract}
From an international perspective, the European rate of unemployment has been high and growing over the last one to two decades; against this background, the parallel rise in profit shares in a number of European countries seems to be at odds with expected economic behaviour.

This paper contributes to a solution of this apparent enigma in two steps. First, an empirical decomposition for two sub-periods (1966-81 and 1981-96) suggests that the rise in profit shares during the second sub-period primarily originated from three sources: a marked fall in real capital prices, a clear upward shift of the return to capital as a result of wage moderation, and a slowdown in the rate of growth of the capital/labour ratio, compared with the first sub-period.

Second, based on various estimates of elasticities of substitution, this slowdown is analysed in greater depth. From the evidence it appears that the adjustment of firms to growing profits and falling user cost of capital compared with wages is, in some sense, sub-optimal. In the short run firms do not substitute capital for labour in full accordance with cost-minimising prescriptions and the speed of convergence towards a complete substitution is slow. Hence, during this transitional period, both investment and labour productivity growth have been relatively low.
\end{abstract}

Keywords: investment, factor substitution, unemployment, profit share and labour productivity.

JEL classification: E0, E2 and J3.

* The first two authors are affiliated with the Bank for International Settlements in Basle, Switzerland and the first and third authors with the Institute of Economics, University of Aarhus, Denmark. We gratefully acknowledge the graphical work by S Arthur and comments on earlier drafts by M Dueker, G Galati, H Pagès, W Wascher and several colleagues at the Institute of Economics, University of Aarhus. The views expressed are entirely those of the authors and are not necessarily shared by their respective employers. 



\section{Contents}

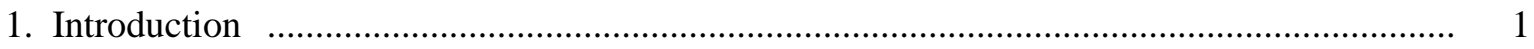

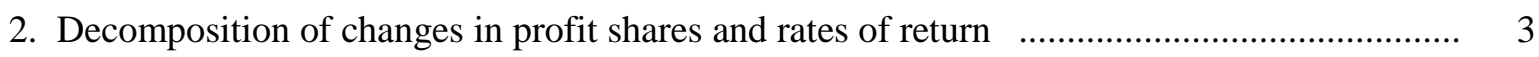

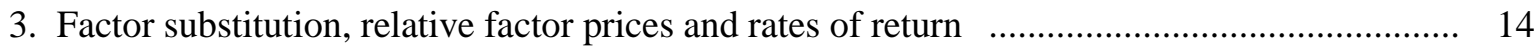

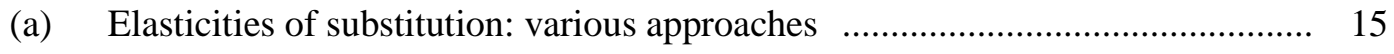

(b) Changes in factor proportions and ex post relative returns f........................... 18

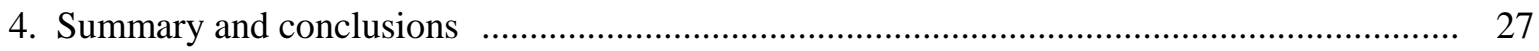

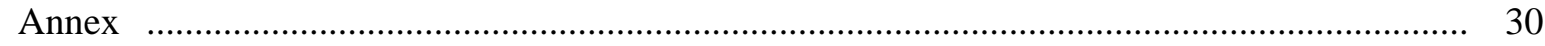

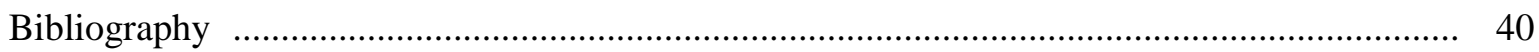





\section{Introduction}

The trend rise in unemployment is a problem that has occupied European policy-makers for more than twenty years. Much less noticed is the fact that, parallel to the rise in unemployment since the early 1980s, profit shares and rates of return to capital have also increased in a number of continental European countries. This is in marked contrast to the 1970s, when rising unemployment was accompanied by falling profits. ${ }^{1}$

According to most theories, a parallel rise in profits and unemployment would eventually lead to a correction whereby both profit shares and unemployment decline towards their equilibrium levels. Capital/labour ratios would be expected to increase and the resulting rise in labour productivity would boost firms' demand for labour, unless, of course, wage claims rise in step with or exceed labour productivity. However, even though the last fifteen years have seen a marked rise in capital/labour ratios, employment growth has remained subdued, notably in continental Europe. One explanation might be that the factor substitution process has not been accompanied by sufficient growth of overall demand. Alternatively, firms' attempts to cut costs, combined with a fall in the relative price of capital, may have imparted a capital deepening bias to investment.

However, slow employment growth in Europe is not the only puzzle. Another is that, contrary to what theory would have predicted, the shift in factor ratios in favour of capital has not generated lower rates of return to capital; in fact, since the early 1980s rates of return have generally increased, reversing a downward trend observed during the previous fifteen years. One explanation for the rise in returns might be that the period 1981-96 was a period of transition between two equilibria, owing to the large changes in relative factor prices and the limited speed with which factor ratios are adjusted. ${ }^{2}$ This hypothesis seems to be quite well supported by the data and also helps to explain why investment has not been more responsive to the improvement in profits and the fall in the relative cost of capital. Moreover, when we use an error-correction model, allowing for transitional lags as well as a partial influence of demand-side developments and changes in the distribution of rents, most of the puzzling increase in the ex post relative return to capital can be explained.

Nonetheless, given higher profits, lower capital costs and relatively favourable financing conditions, it cannot be excluded that capital formation has been too low and/or that other factors have dampened

1 Profits refer to the financial and non-financial business sector and a more appropriate term would be the capital income share. In the following we shall use profits and capital income interchangeably. Blanchard (1997) is the first to have noticed the parallel rise in European unemployment and profit shares. In his analytical and empirical work, he distinguishes between two groups of countries: the United States, the United Kingdom and Canada, on the one hand, and "continental Europe" (broadly defined to include Australia), on the other. The divergent changes in profit shares and unemployment in Europe are also analysed in Caballero and Hammour (1998) who, on page 54, succinctly describe the last fifteen years as a period where: "Capital and labour in Europe seem to have parted company, with capital growing at sustained rates and yielding returns comparable to the 1960s, while labour seems to be following a much gloomier path".

2 Alternatively, the rise in returns could reflect a shift in bargaining power in favour of capital or technical changes biased against labour, especially workers with low skills. 
investment spending. For instance, changes in the sectoral composition of output, combined with differences in capital/output ratios, might have reduced the growth of the aggregate capital stock. We have briefly analysed this issue but from the evidence (which we do not report) it appears that while sectoral differences and shifts can be observed they have been too small to exert a major impact. It has also been suggested that capital stocks are approaching saturation points. Again, however, the hypothesis is not well supported by the data as actual capital/output ratios are well below those implied by "golden rules" of accumulation.

Section 2 of the paper analyses the immediate sources of changes in profit shares and rates of return. Unlike the earlier literature on the 1966-81 fall in profit shares (see, for instance, Bruno and Sachs (1985)), which mostly relied on differential changes in real wages and labour productivity, we develop a decomposition scheme which attributes a major part of the movements in profits and profitability to changes in capital/labour ratios, real profits per person employed and the real price of capital. ${ }^{3}$

Section 3 then turns to the underlying factor adjustment functions, drawing on several aspects of other recent analyses. Like Blanchard (1997) and Caballero and Hammour (1998), we focus on the supply side by estimating elasticities of substitution, using several models and specifications. We also look at the interaction between technological factors and attempts by capital and labour to appropriate rents in analysing recent developments in returns to capital and labour. More specifically, we do so by estimating equations for ex post returns and factor income shares. In addition to changes in factor ratios, these estimates include the rate of unemployment, as a measure of relative bargaining power, and the real interest rate, as an indicator of upward pressure on profit margins and/or the rate of unemployment (see Phelps (1994)). Despite their intuitive and analytical appeal, we do not estimate putty-clay production functions but rely on putty-putty functions with long adjustment lags. Similarly, we do not attempt to find shifts in the nature of recent technical changes, which might explain lower income shares for labour in general and low-skilled workers in particular. ${ }^{4}$ Finally, while also relying on the OECD Business Sector Data Base as our primary source, we do not aggregate the data into representative country groups but rather attempt to identify common features from production and adjustment functions estimated separately for each of the seventeen countries in the sample.

Section 4 summarises the empirical evidence and derives conclusions. It also points to areas in need of further research, in particular a broader analysis of demand-side effects with respect to labour demand

3 Note that throughout this paper, capital stocks are measured net of scrapping, and not net of depreciation. It is debatable which measure is more appropriate but the argument by Kirova and Lipsey (1997) that reinvestments contain more advanced technologies than the capital stocks they replace persuaded us to use the broader measure. This also meant that we had to construct capital stocks for the United States, which are now published only net of depreciation.

4 While recognising their potential relevance to this paper we have not taken account of recent papers providing evidence of changes in the nature of technical progress in favour of capital and skilled workers (see contributions in the November 1998 issue of the Quarterly Journal of Economics (pp. 1169-1308)); data limitations forced us to assume both capital and labour to be homogeneous inputs. 
and unemployment and the influence of changes in financial markets and corporate finance structures on investment and capital ratios.

In the Annex, we briefly look at changes in investment/output ratios, noting that the trend decline is most pronounced when measured in current prices and that it has not prevented investment per employee from rising. We also explore the issue of saturation by calculating capital stock and investment ratios according to "golden rule" criteria and then comparing them with actual ratios.

\section{Decomposition of changes in profit shares and rates of return}

While the 1970s were a period of generally declining profit shares and rates of return to capital, this trend has been reversed over the last fifteen years. At first glance, the reversal is not surprising. Assuming a two-factor production function with constant returns to scale and an elasticity of substitution close to unity, neoclassical theory would predict that the functional distribution of income should be stationary. However, what is surprising is that, in several countries, the return of profit shares to the levels of the 1960s seems to have been accompanied by growing disequilibria in labour markets. This is clearly evident in Germany, France, Italy and Spain (Graph 1a), where profit shares and unemployment show a significant positive correlation in the 1980s and 1990s. A similar trend can be observed in some of the Nordic countries (Graph 1b), whereas, in Japan and Switzerland, higher unemployment has been accompanied by declining profits.

In contrast, the Netherlands, Ireland and Belgium have combined rising profit shares with falling unemployment (Graph 1c). This combination is even more striking in the United States, where the drop in the rate of unemployment to the lowest level for almost thirty years has coincided with strong profit growth (Graph 1d). The United Kingdom has also experienced a marked improvement in labour market conditions but, unlike in the United States, unemployment and profits seem to be positively correlated. Australia and Canada are similar in the sense that changes in unemployment and profits do not seem to be systematically related. However, while Australia has seen a significant rise in profits since the early 1980s, the profit share of Canadian companies has fallen. 
Graph 1a

Unemployment rates and profit shares

Germany

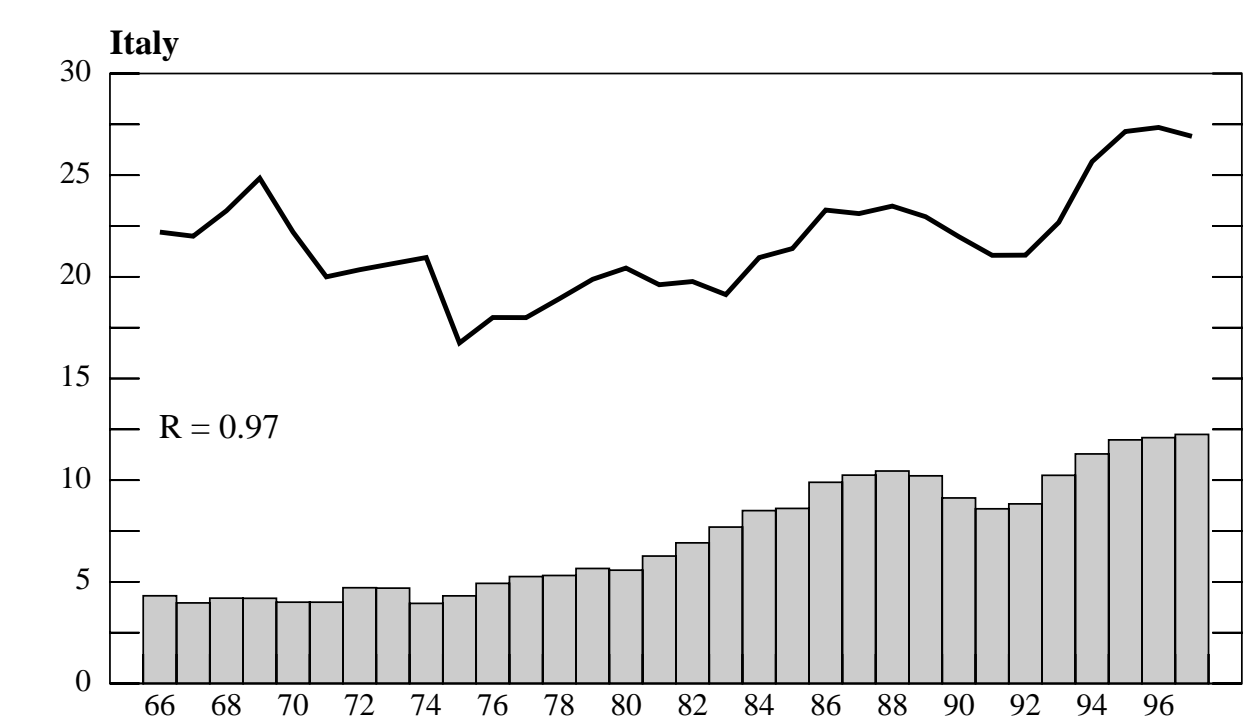

France

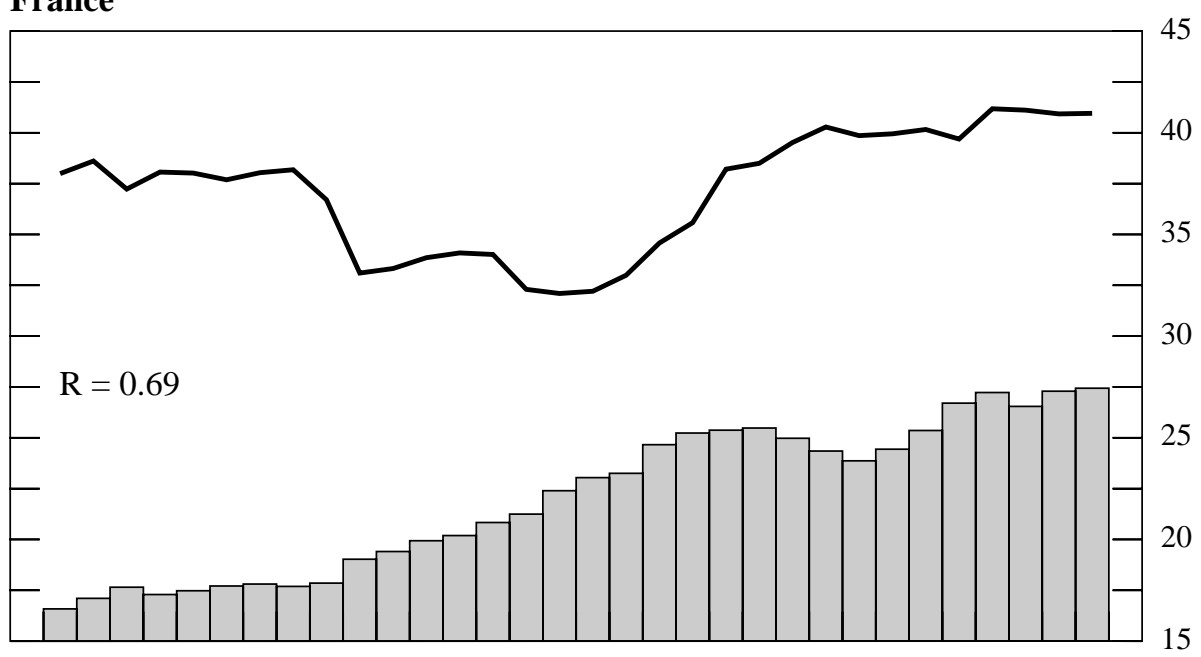

Spain

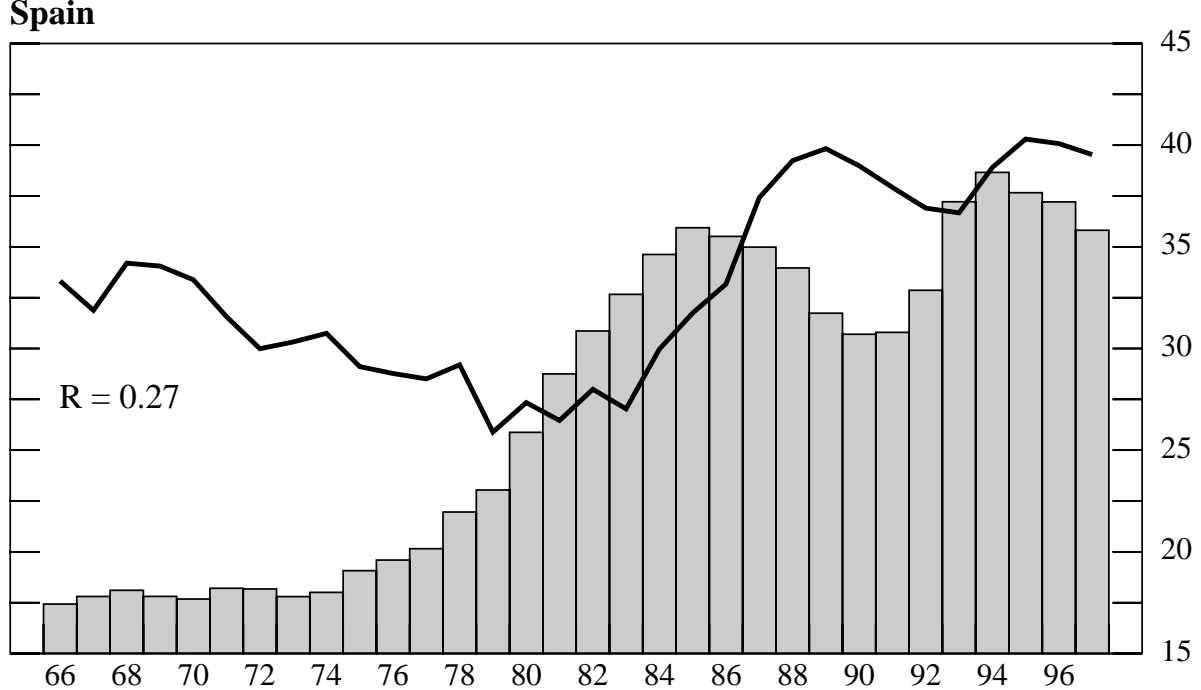

Note: The correlation coefficients are estimated over the period $1982-97$ 
Graph 1b

Unemployment rates and profit shares

Sweden
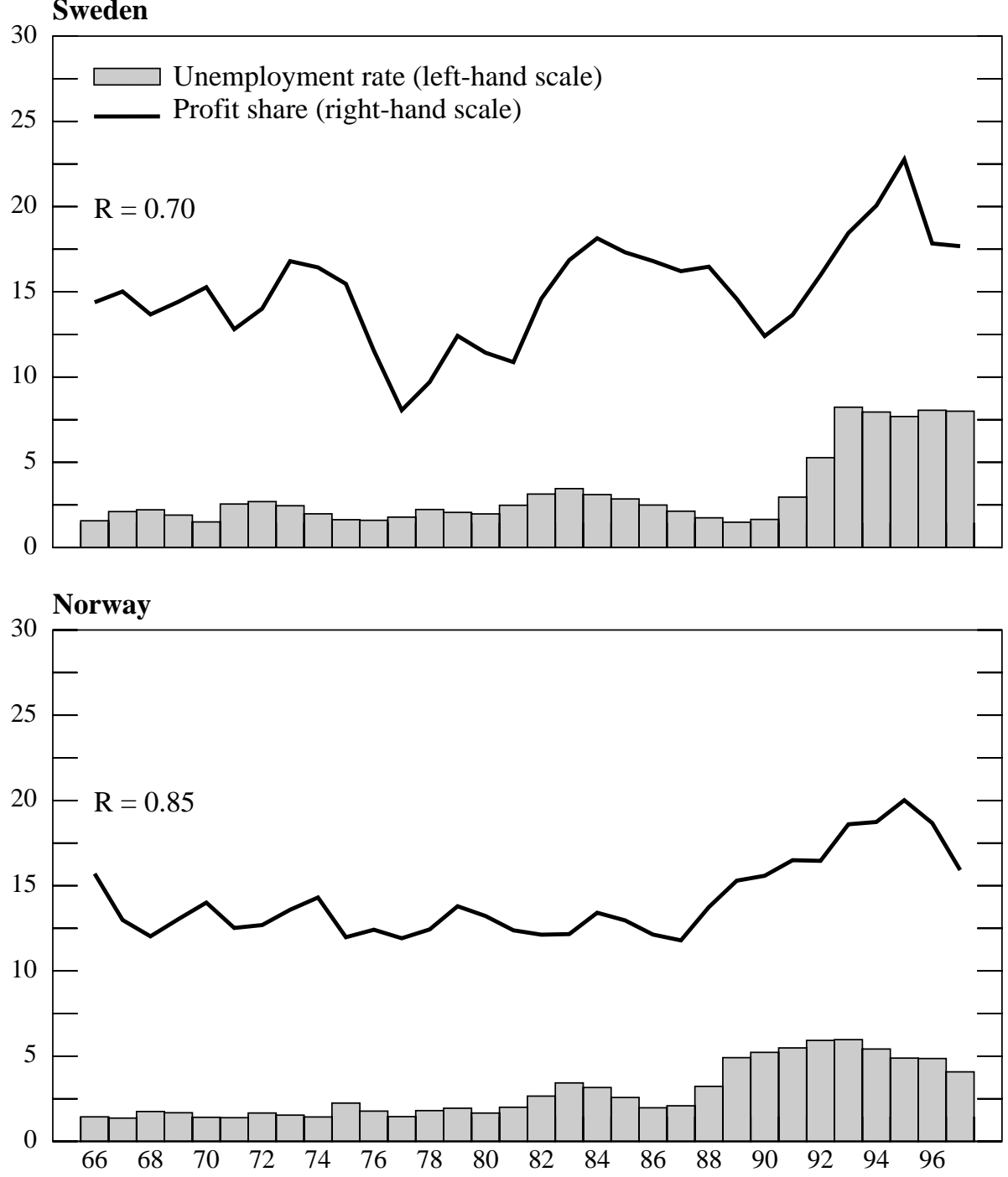

Finland

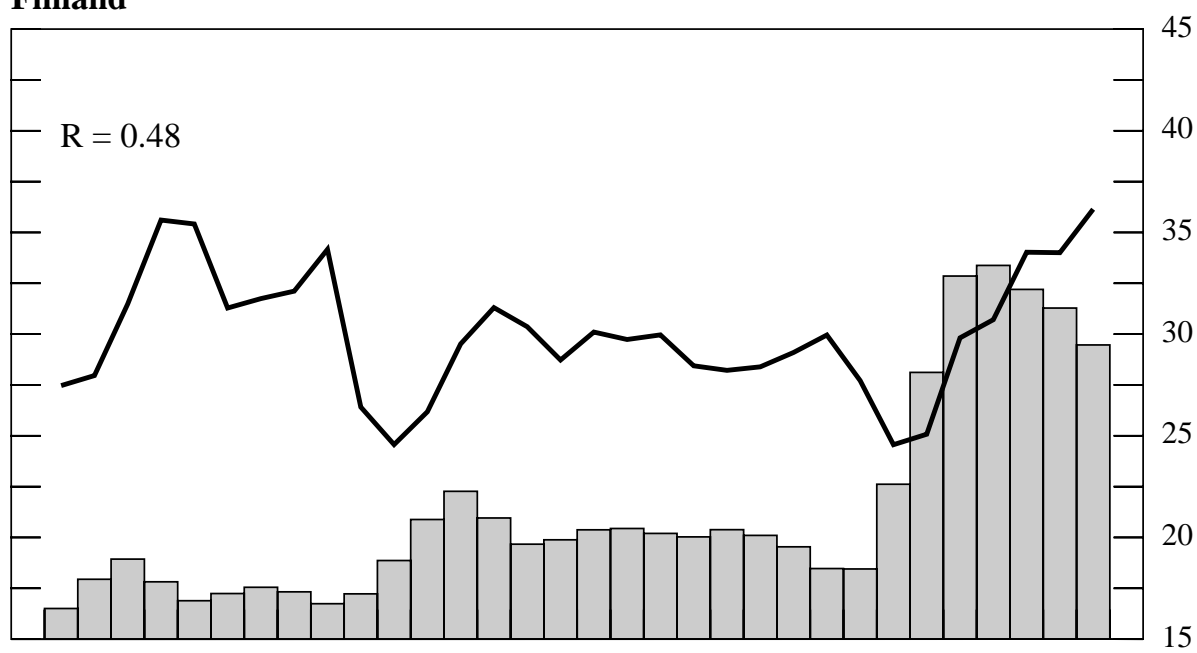

\section{Denmark}

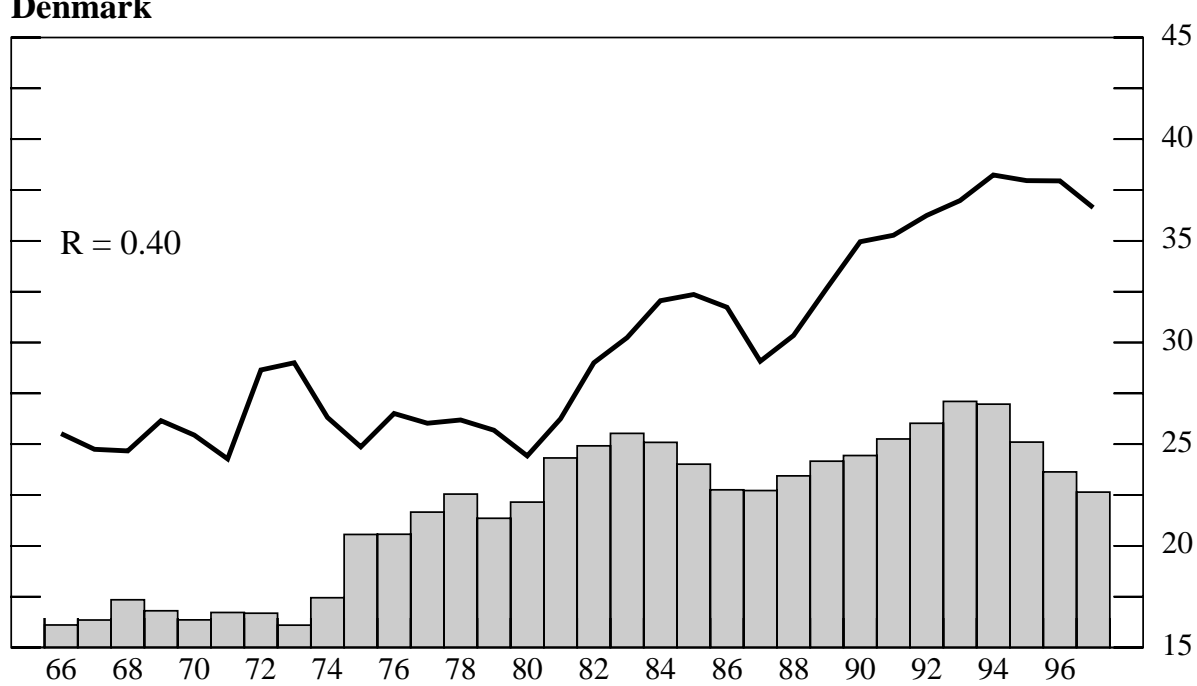

Note: The correlation coefficients are estimated over the period $1982-97$ 
Graph 1c

Unemployment rates and profit shares

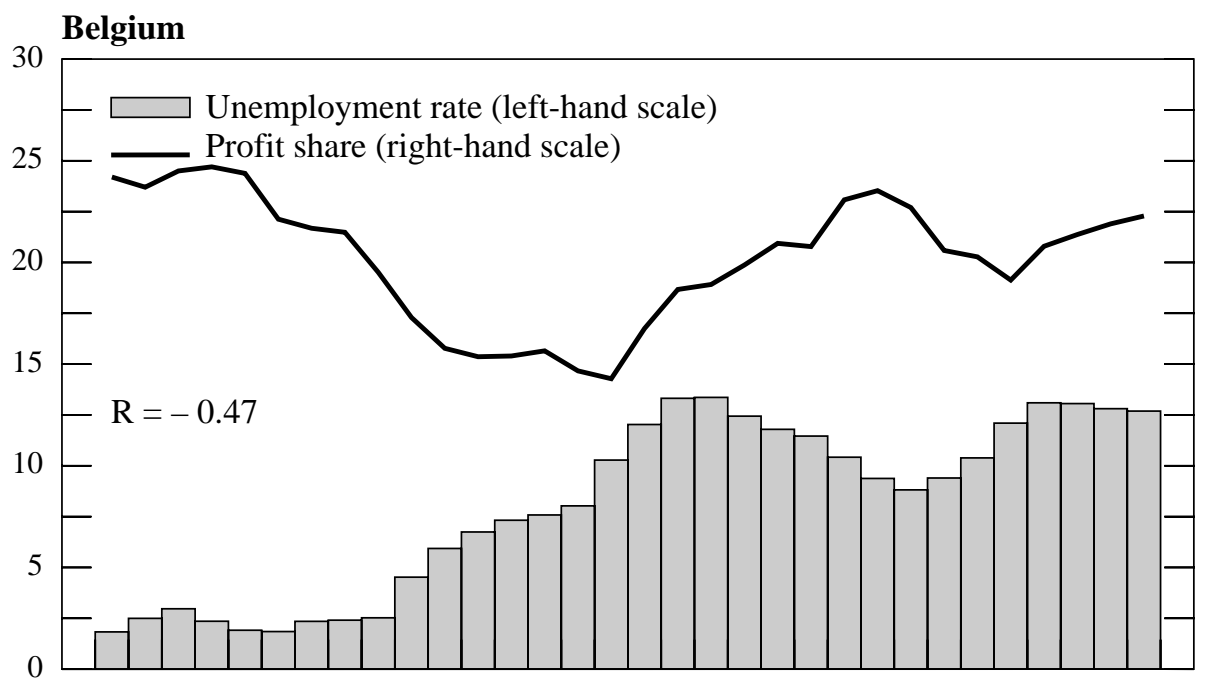

Netherlands
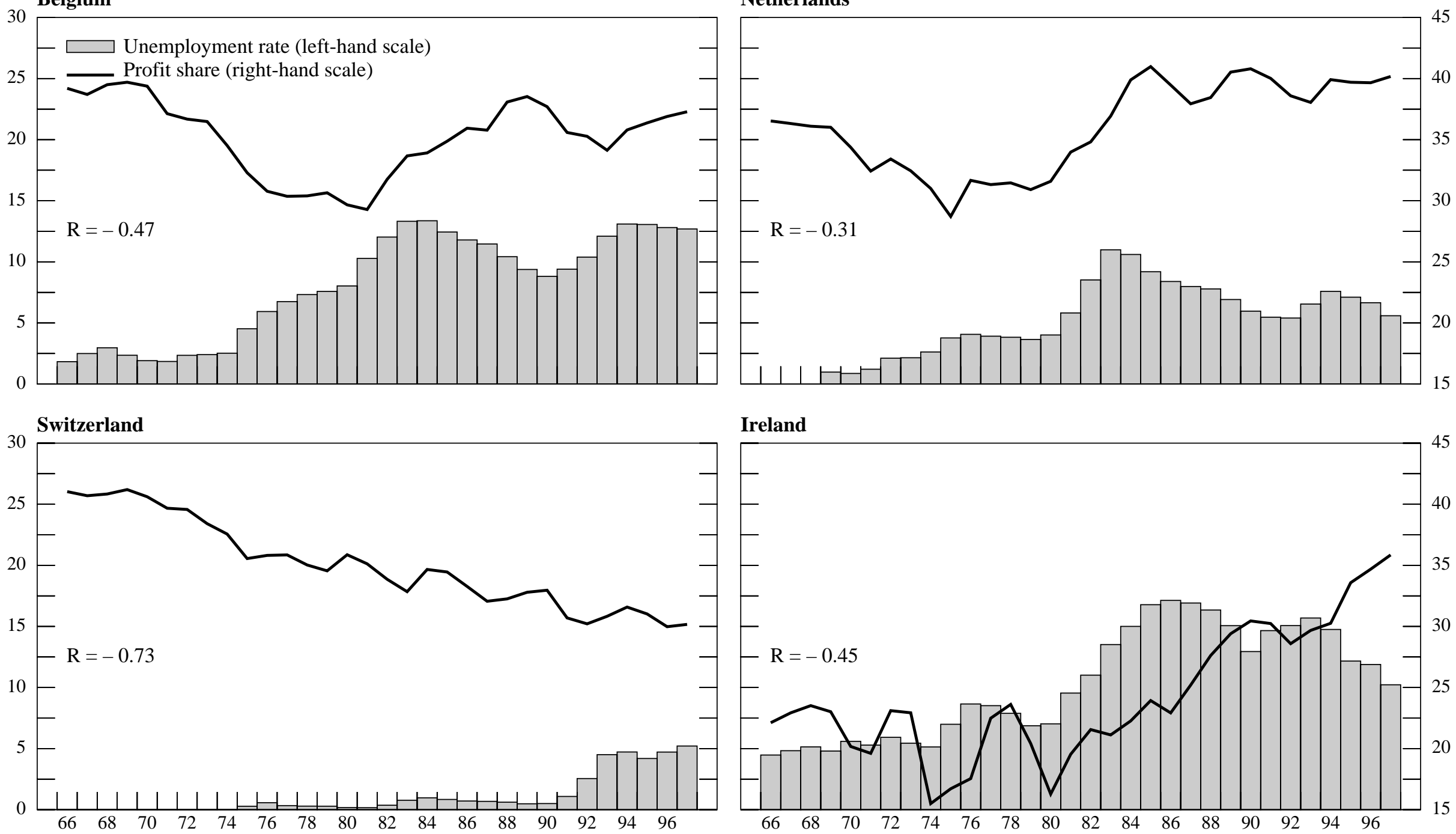

Ireland

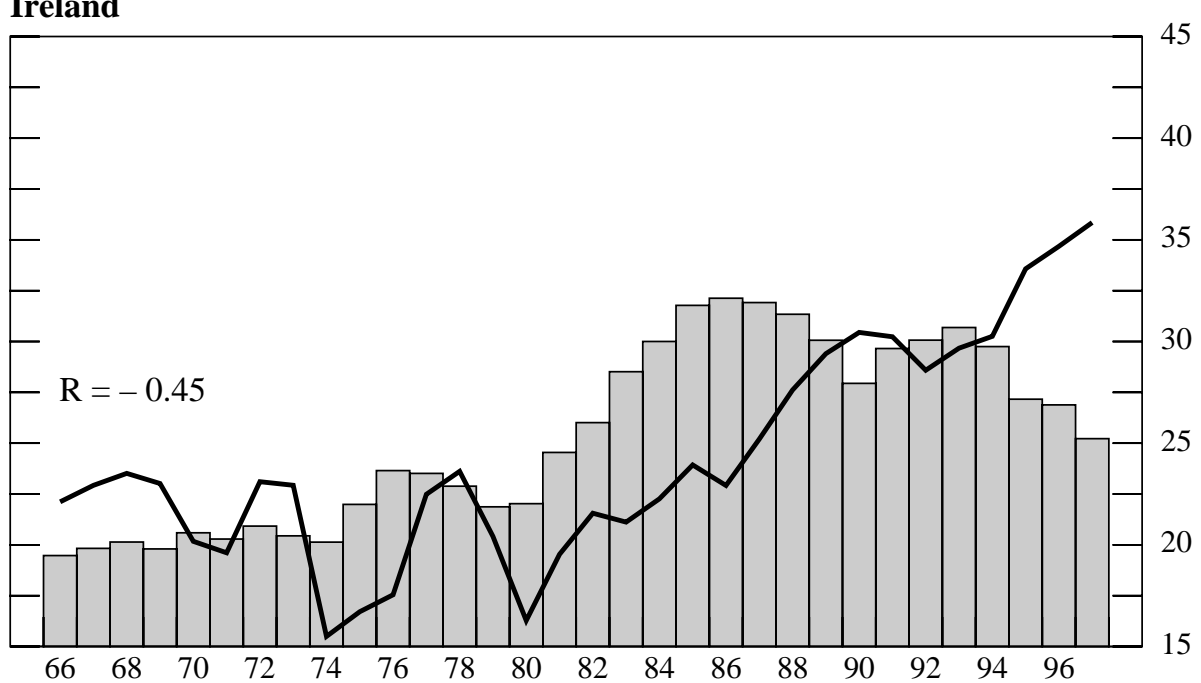

Note: The correlation coefficients are estimated over the period $1982-97$. 
Graph 1d

Unemployment rates and profit shares

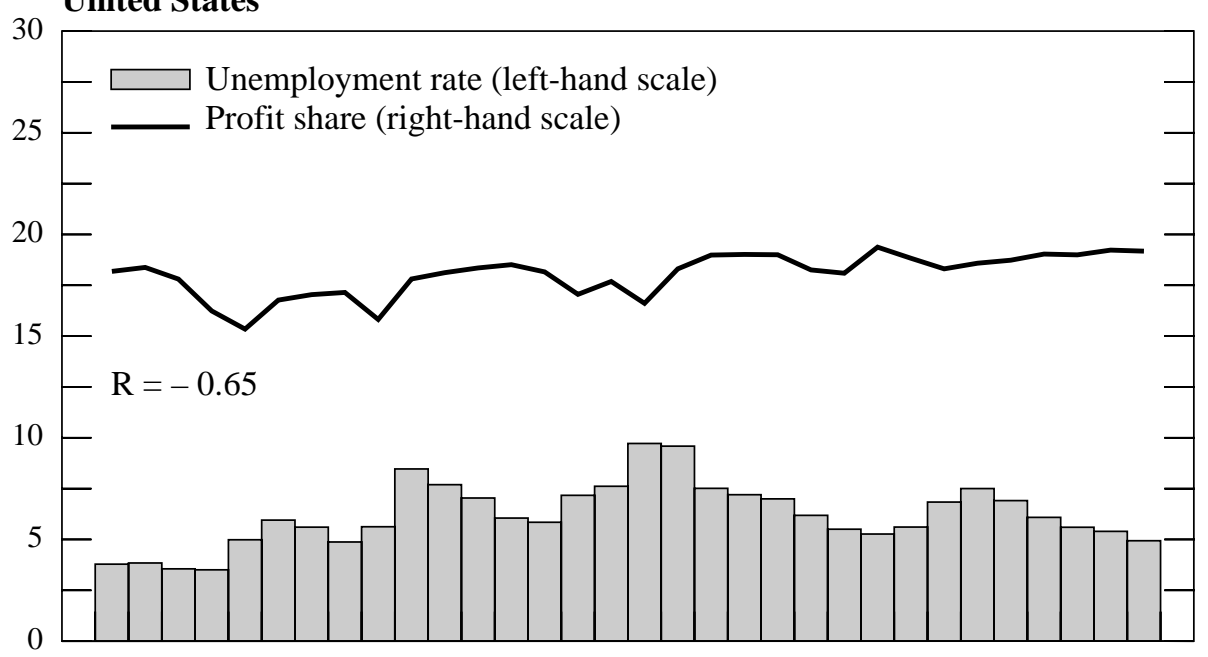

United States

\section{United Kingdom}

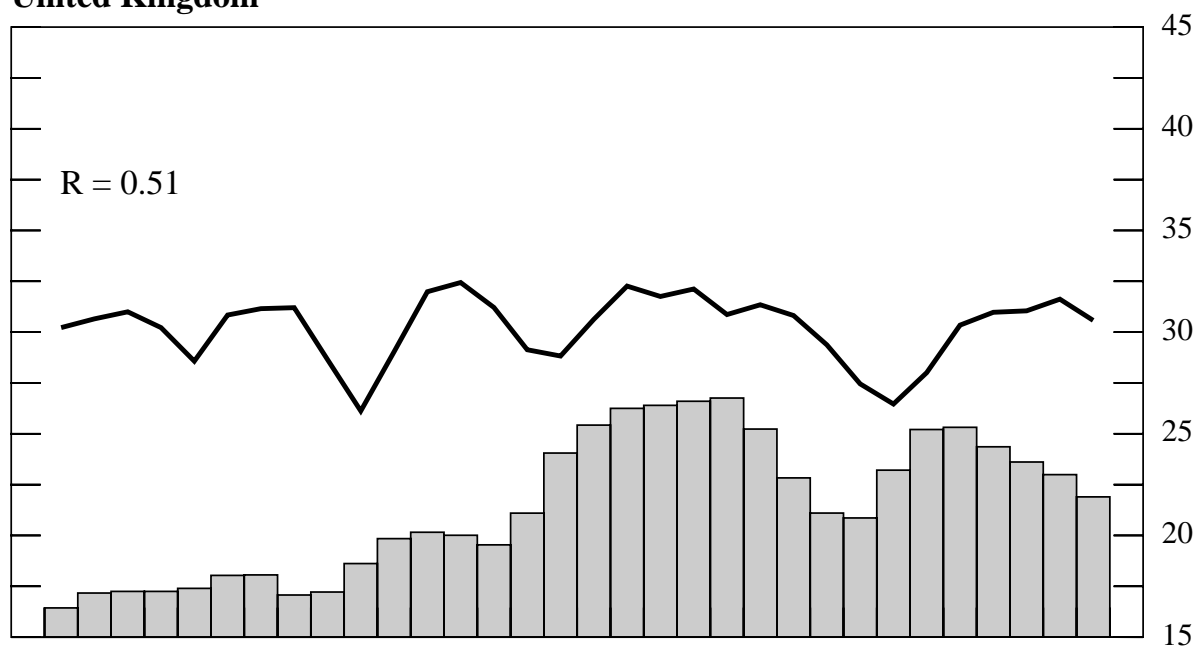

\section{Australia}
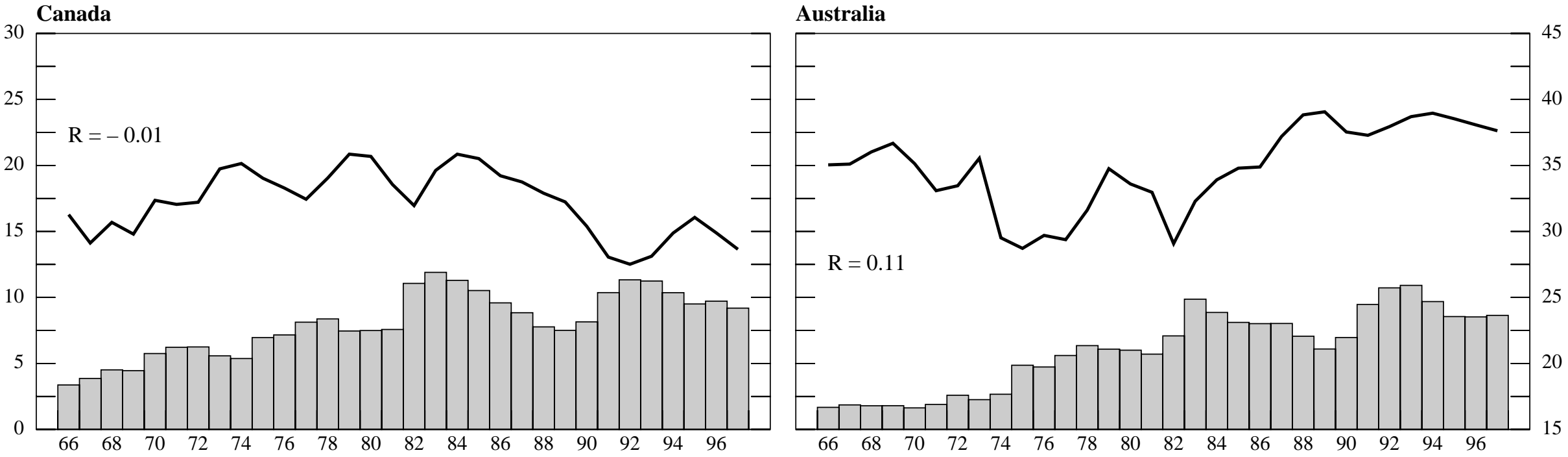

Note: The correlation coefficients are estimated over the period $1982-97$ 
Table 1

Various indicators of profit share developments

\begin{tabular}{|c|c|c|c|c|c|c|}
\hline \multirow[t]{2}{*}{ Countries } & \multirow[t]{2}{*}{ Period } & \multirow[t]{2}{*}{ Mean } & \multirow[t]{2}{*}{$\begin{array}{l}\text { Standard } \\
\text { deviation }\end{array}$} & \multicolumn{3}{|c|}{$\begin{array}{c}\text { Integration tests, } \\
t \text {-values for } \beta \text {-coefficients* }\end{array}$} \\
\hline & & & & Level & Trend & 1st difference \\
\hline United States & 1961-97 & 32.9 & 1.31 & -2.81 & no & -6.25 \\
\hline Canada & $1966-97 * *$ & 32.0 & 2.53 & -1.95 & no & -4.21 \\
\hline United Kingdom & 1962-97 & 30.3 & 1.53 & -5.10 & no & -6.05 \\
\hline Australia & 1965-97 & 35.1 & 3.07 & -1.75 & no & -4.81 \\
\hline Japan & 1965-97 & 34.0 & 4.33 & -1.96 & no & -3.20 \\
\hline Germany & 1960-97 & 35.5 & 2.36 & -1.64 & no & -4.18 \\
\hline \multirow[t]{2}{*}{ France } & 1965-97 & 37.4 & 3.02 & -1.04 & no & -4.25 \\
\hline & & & & -1.55 & yes $(+)$ & - \\
\hline \multirow[t]{2}{*}{ Italy } & $1966-97 * *$ & 37.1 & 3.01 & -1.24 & no & -4.89 \\
\hline & & & & -1.71 & yes $(+)$ & - \\
\hline Belgium & 1966-97 & 35.3 & 3.11 & -1.73 & no & -3.75 \\
\hline \multirow[t]{2}{*}{ Denmark } & $1961-97 * *$ & 29.8 & 4.57 & -0.66 & no & -5.01 \\
\hline & & & & -2.60 & yes $(+)$ & - \\
\hline Finland & $1962-97 * *$ & 30.4 & 3.16 & -3.35 & no & -4.75 \\
\hline \multirow[t]{2}{*}{ Ireland } & 1961-97 & 25.2 & 5.73 & -0.71 & no & - \\
\hline & & & & -1.73 & yes $(+)$ & -5.32 \\
\hline \multirow[t]{2}{*}{ Netherlands } & $1966-97 * *$ & 36.7 & 4.09 & -1.86 & no & -4.10 \\
\hline & & & & -3.32 & yes $(+)$ & - \\
\hline Norway & 1963-97 & 29.4 & 2.25 & -2.05 & no & -4.08 \\
\hline \multirow[t]{2}{*}{ Spain } & $1964-97 * *$ & 33.5 & 4.64 & -0.80 & no & -3.00 \\
\hline & & & & -1.84 & yes (+) & - \\
\hline Sweden & 1965-97 & 30.3 & 2.88 & -2.83 & no & -4.57 \\
\hline \multirow[t]{2}{*}{ Switzerland } & 1960-97 & 35.9 & 4.22 & -1.12 & no & - \\
\hline & & & & -3.08 & yes $(-)$ & -6.34 \\
\hline \multicolumn{7}{|c|}{$\begin{array}{l}* \text { Test equation specified as: } \Delta y_{t}=\alpha+\beta y_{t-1}+\delta \Delta y_{t-i} \text {, with } i=1 \ldots .4 \text {. Critical significance values for t-ratios } \\
\text { ( } 50 \text { observations): } 2.62(1 \%), 1.95(5 \%) \text { and } 1.61(10 \%) \text {. } \\
* * \text { Profit share estimated from OECD database for first } 10-15 \text { years of the period. } \\
\text { Source } \text { OECD Business Sector Data Base. }\end{array}$} \\
\hline
\end{tabular}

These deviations from the predictions of neoclassical theory are further illustrated in Table 1, which tests the time series properties of profit shares. In most continental European countries, and in Ireland and Australia as well, profit shares seem to be non-stationary, though in two-thirds of the cases stationary behaviour is found when allowing for a positive (negative in the case of Switzerland) trend. In contrast, for the United States, Japan, the United Kingdom, Canada and three of the Nordic countries, the null hypothesis of a stationary time pattern cannot be rejected, even without including a time trend. It is also notable, that the average profit share differs between countries. It is relatively high in most of continental Europe, Japan and Australia, whereas the Nordic countries and Ireland have much lower profit shares. The US profit share is close to the centre of the range and has been more stable than that of other countries. 
As an initial step in exploring the sources of changes in rates of return and profit shares and how they have differed between countries, we used two accounting identities to select the relevant components (see also Poterba (1997)). First, by definition, the share of profits $(S)$ in a given year can be written as:

$$
S=\left(Y P_{y}-W E m\right) / Y P_{y}=\left(Y / E m-W / P_{y}\right)(E m / Y)=\left(Y / E m-W / P_{y}\right)(E m / K)(K / Y)
$$

where $Y=$ output (or value added), $P_{y}=$ output (or value added) deflator, $E m=$ employment, $W=$ compensation per employee and $K=$ capital stock. While (i) is an identity, we may assume that, over time, the four components can be approximated by individual exponential functions, so that:

$$
S_{o} e^{s t}=Z_{o} e^{z t} X_{o} e^{x t} V_{o} e^{v t} \varphi_{t} \text { or, by differentiating with respect to } t \text { : }
$$

$$
s=z+x+v+\varphi
$$

where $\varphi$ " is a residual which "collects" discrepancies between the two sides of the equation.

Second, the rate of return $(R)$ can be linked to the profit share by the identity:

$$
\left.R=S\left(Y P_{y}\right) / K P_{k}\right)
$$

where $P_{k}$ is the price of capital goods. By analogy with the approximation used above, (iv) can be rewritten as:

$$
\begin{aligned}
& R_{o} e^{r t}=Z_{o} e^{z t} X_{o} e^{x t} F_{o} e^{f t} \psi_{t} \text { or } \\
& r=z+x+f+\psi^{\prime}
\end{aligned}
$$

where $F$ denotes the price ratio $P_{y} / P_{k}$. Thus $r$ is obtainable from $s$ by replacing the trend of $K / Y(v)$ by the trend of $P_{y} / P_{k}(f)$. The trends of the "explanatory" components discussed above are shown for two sub-periods in Table 2 and Graph 2, together with the corresponding changes in rates of return and profit shares. To facilitate the reading of the table, we have denoted $Y / E m$ by $q$ (labour productivity) and $W / P_{y}$ by $w r$ (real wages), and below we shall frequently refer to $\Delta(w r-q)$ as the change in real unit labour costs or in the mark-up. ${ }^{5}$

As noted above, one remarkable feature of the last fifteen years is the recovery of profit shares and rates of return, following marked falls in most of the countries during 1966-81. This turnaround is usually attributed to the moderation of nominal and real wage growth, in particular in continental Europe. Indeed, as the table shows, real wage growth exceeded productivity gains by an average 0.3 percentage points during 1966-81, creating a real wage "gap" or "overhang".

5 To clarify this concept, it might be helpful to rewrite equation (ii) as a mark-up function for the output price: $P_{y}=\mu(W /(Y / E m))$ or, by taking logs and using the notation introduced above: $\log \mu=\log \left(P_{y} / W\right)(Y / E m)=(q-w r)$. Thus, changes in the mark-up would be equivalent to changes in real unit labour costs $(w r-q)$ with the sign reversed. 
Table 2

Decomposition of changes in profit shares and rates of return

Annual trend rates of change, in percentages

\begin{tabular}{|c|c|c|c|c|c|c|c|c|c|}
\hline 1966-81 & $S$ & $q$ & $w r$ & $(q-w r)$ & $(e m-k)$ & $(k-y)$ & $\left(p_{k}-p_{y}\right)$ & $R$ & $e_{q,(k-e m)}$ \\
\hline United States & 0.13 & 0.96 & 0.90 & 1.09 & -0.85 & -0.11 & 0.01 & 0.23 & 1.13 \\
\hline Japan & -2.97 & 5.01 & 6.80 & 1.89 & -8.37 & 3.93 & -1.51 & -5.39 & 0.60 \\
\hline Germany & -1.21 & 3.48 & 4.14 & 2.22 & -4.29 & 0.98 & -0.11 & -2.08 & 0.81 \\
\hline France & -1.27 & 3.79 & 4.52 & 2.47 & -4.27 & 0.65 & 0.13 & -2.05 & 0.89 \\
\hline Italy & -0.81 & 3.61 & 4.09 & 2.77 & -3.41 & -0.07 & 1.51 & -2.25 & 1.06 \\
\hline United Kingdom & -0.12 & 2.62 & 2.66 & 2.50 & -3.58 & 1.07 & 1.22 & -2.41 & 0.73 \\
\hline Canada & 1.03 & 2.14 & 1.63 & 3.19 & -4.06 & 2.06 & -1.33 & 0.30 & 0.53 \\
\hline Australia & -0.83 & 2.42 & 2.85 & 1.57 & -2.84 & 0.49 & 0.42 & -1.74 & 0.86 \\
\hline Belgium & -2.36 & 3.97 & 5.28 & 1.52 & -4.37 & 0.58 & -0.69 & -2.25 & 0.91 \\
\hline Denmark & 0.12 & 2.88 & 2.84 & 3.00 & -5.04 & 2.36 & 0.33 & -2.57 & 0.57 \\
\hline Finland & -0.56 & 4.20 & 4.46 & 3.61 & -4.10 & 0.08 & 1.09 & -1.73 & 1.02 \\
\hline Ireland & -1.29 & 4.98 & 5.31 & 3.63 & -3.70 & -1.08 & 1.00 & -1.21 & 1.35 \\
\hline Netherlands & -0.65 & 3.16 & 3.49 & 2.48 & -2.98 & -0.08 & -0.22 & -1.08 & 1.06 \\
\hline Norway & -0.25 & 3.07 & 3.17 & 2.81 & -3.31 & 0.35 & 1.40 & -2.00 & 0.93 \\
\hline Spain & -1.68 & 4.59 & 5.36 & 2.83 & -8.89 & 4.95 & -1.74 & -4.89 & 0.92 \\
\hline Sweden & -1.12 & 2.35 & 2.78 & 1.20 & -5.16 & 3.03 & -1.01 & -3.14 & 0.77 \\
\hline Switzerland & -1.32 & 1.94 & 2.77 & 0.60 & -4.06 & 2.24 & -1.54 & -2.02 & 0.87 \\
\hline Average* & -0.9 & 3.2 & 3.5 & 2.3 & -4.3 & 1.2 & -0.1 & -2.0 & 0.75 \\
\hline
\end{tabular}

\begin{tabular}{|c|c|c|c|c|c|c|c|c|c|}
\hline 1981-96 & $S$ & $q$ & $w r$ & $(q-w r)$ & $(e m-k)$ & $(k-y)$ & $\left(p_{k}-p_{y}\right)$ & $R$ & $e_{q,(k-e m)}$ \\
\hline United States & 0.25 & 0.93 & 0.80 & 1.18 & -0.90 & -0.01 & -1.91 & 2.17 & 1.03 \\
\hline Japan & 0.79 & 2.41 & 2.11 & 3.30 & -4.14 & 1.86 & -1.44 & 0.37 & 0.58 \\
\hline Germany & 0.93 & 2.47 & 1.97 & 3.42 & -2.32 & -0.09 & -0.52 & 1.54 & 1.06 \\
\hline France & 1.74 & 2.29 & 1.27 & 4.07 & -2.57 & 0.34 & -0.93 & 2.33 & 0.89 \\
\hline Italy & 1.10 & 2.26 & 1.58 & 3.38 & -2.65 & 0.46 & -1.51 & 2.15 & 0.85 \\
\hline United Kingdom & -0.39 & 1.64 & 1.88 & 1.31 & -1.32 & -0.29 & -0.89 & 0.79 & 1.24 \\
\hline Canada & -1.32 & 1.16 & 1.78 & -0.18 & -4.31 & 3.31 & -2.69 & -1.94 & 0.27 \\
\hline Australia & 1.66 & 1.38 & 0.43 & 3.01 & -1.54 & 0.19 & -0.93 & 2.40 & 0.90 \\
\hline Belgium & 0.91 & 1.82 & 1.36 & 2.75 & -2.56 & 0.79 & -1.03 & 1.15 & 0.71 \\
\hline Denmark & 2.21 & 2.13 & 1.03 & 4.38 & -2.72 & 0.66 & -1.12 & 2.67 & 0.78 \\
\hline Finland & 0.42 & 3.75 & 3.53 & 4.18 & -4.14 & 0.55 & -0.02 & -0.11 & 0.90 \\
\hline Ireland & 3.62 & 4.07 & 2.77 & 7.82 & -1.69 & -2.26 & -0.92 & 6.80 & 2.41 \\
\hline Netherlands & 0.65 & 1.57 & 1.19 & 2.23 & -0.88 & -0.68 & 0.11 & 1.22 & 1.78 \\
\hline Norway & 1.88 & 1.91 & 1.03 & 3.77 & -2.46 & 0.60 & -0.02 & 1.30 & 0.78 \\
\hline Spain & 2.97 & 2.42 & 1.02 & 5.54 & -3.56 & 1.23 & -1.42 & 3.16 & 0.68 \\
\hline Sweden & 1.05 & 2.14 & 1.57 & 3.14 & -3.13 & 1.07 & -2.10 & 2.08 & 0.68 \\
\hline Switzerland & -0.91 & 0.36 & 0.80 & -0.56 & -1.56 & 1.23 & -2.57 & 0.43 & 0.23 \\
\hline Average* & 1.1 & 2.0 & 1.4 & 3.1 & -2.5 & 0.5 & -1.1 & 1.7 & 0.80 \\
\hline
\end{tabular}

* Unweighted.

Over the next fifteen years, by contrast, productivity gains exceeded real wage growth by twice that amount, as real wage moderation went well beyond the slowdown in productivity gains. The shift was 
particularly marked in the four largest continental European countries, for which the discrepancy averaged 0.9 percentage points. However, it was also notable in several smaller European countries, Japan and Australia. In Switzerland, on the other hand, real unit labour costs continued to grow and Canada has gone against the common trend in both periods. During 1966-81, real unit labour costs declined, thus boosting profits. However, over the next fifteen years, real unit labour costs increased, as real wages seem to have been immune to the slowdown in productivity growth. ${ }^{6}$

While we agree with the consensus analysis, the decomposition schemes explained above allow us to analyse the trends over the two sub-periods from a somewhat different angle. In particular, the approximation by exponential trends contains a difference $\left(Y / E m-W / P_{y}\right)$ and, because the two subcomponents are likely to contain "internal" trends and the outcome thus depends on the initial conditions, the trend of the difference cannot be replaced by the difference between the trends of $Y / E m$ and $W / P_{y}{ }^{7}$ In fact, since profit shares were relatively high in 1966 , real profits per person employed $(q-w r)$ actually increased during the first sub-period, even though real wage growth exceeded productivity gains. At first glance, this seems inconsistent with the recorded fall in profit shares. It should be recalled, however, that changes in labour productivity are not endogenous but depend on changes in the capital/labour ratio. ${ }^{8}$ Consequently, profit shares will be subject to downward pressures if the rise in labour productivity does not "match" the rise in the capital/labour ratio. ${ }^{9}$ On the other hand, such pressures on profit shares (but not on rates of return) will be relieved to the extent that capital/output ratios also increase; see the last component in equations (i) - (iii). ${ }^{10}$

6 According to Freedman and Macklem (1998), there may be several reasons for the comparatively poor productivity and employment performance in Canada. First, due to different time patterns of changes in real exchange rates, restructuring started earlier in the United States (1980-85) than in Canada (1985-90). Second, plants are much larger in the United States than in Canada and large plants tend to adopt new technologies faster than smaller plants. Third, due to differences in labour institutions, wages are more flexible in the United States than in Canada. The data used in this study provide strong support for the third factor as real wages in Canada rose by a cumulative $21 \%$ during the 1980s, compared with only $8 \%$ in the United States, with broadly similar rates of productivity growth. At the same time, there is only little evidence, that restructuring occurred later in Canada than in the United States. Capital/output as well as capital/labour ratios have increased much faster in Canada than in the United States and the rate of growth was slightly faster during 1980-85, when the Canadian real exchange rate was depreciating.

7 When used over longer periods, the approximation also involves a residual, even though equations (iii) and (vi) hold exactly for year-to-year changes.

This is easily seen for a Cobb-Douglas production with constant returns to scale which, in log changes, can be written as: $\Delta y=\alpha \Delta e m+(1-\alpha) \Delta k+e$

where $y$ denotes log output, em log employment, $k \log$ capital and $e$ disembodied technical progress. Subtracting $\Delta e m$ on both sides, we then have:

$(\Delta y-\Delta e m)=\Delta q=(1-\alpha)(\Delta k-\Delta e m)+e$

From this it also appears that the distribution between capital and labour income will only remain constant, if the elasticity of labour productivity with respect to the capital/labour ratio equals unity; cf. the last column in Table 2.

9 As a preliminary indicator of potential downward pressures, we have included ratios between changes in labour productivity and capital/labour ratios in the last column of Table 2.

10

We can illustrate this using the decomposition shown for the average trends in Table 2. For the first period, $(q-w r)$, or real profits per person employed, grew by $2.3 \%$ while the amount of capital per person employed (k-em) grew by $4.3 \%$, so that the difference between the first two components would have generated a trend decline in the profit share of $2.0 \%$ per year. However, the fact that the capital/output ratio grew by $1.2 \%$ during the same period limited the decline in the profit share to $2.0-1.2=0.8 \%$. Allowing for the nature of the approximation, this is quite close to the actually recorded 


\section{Decomposition of profit shares}

In per cent per year
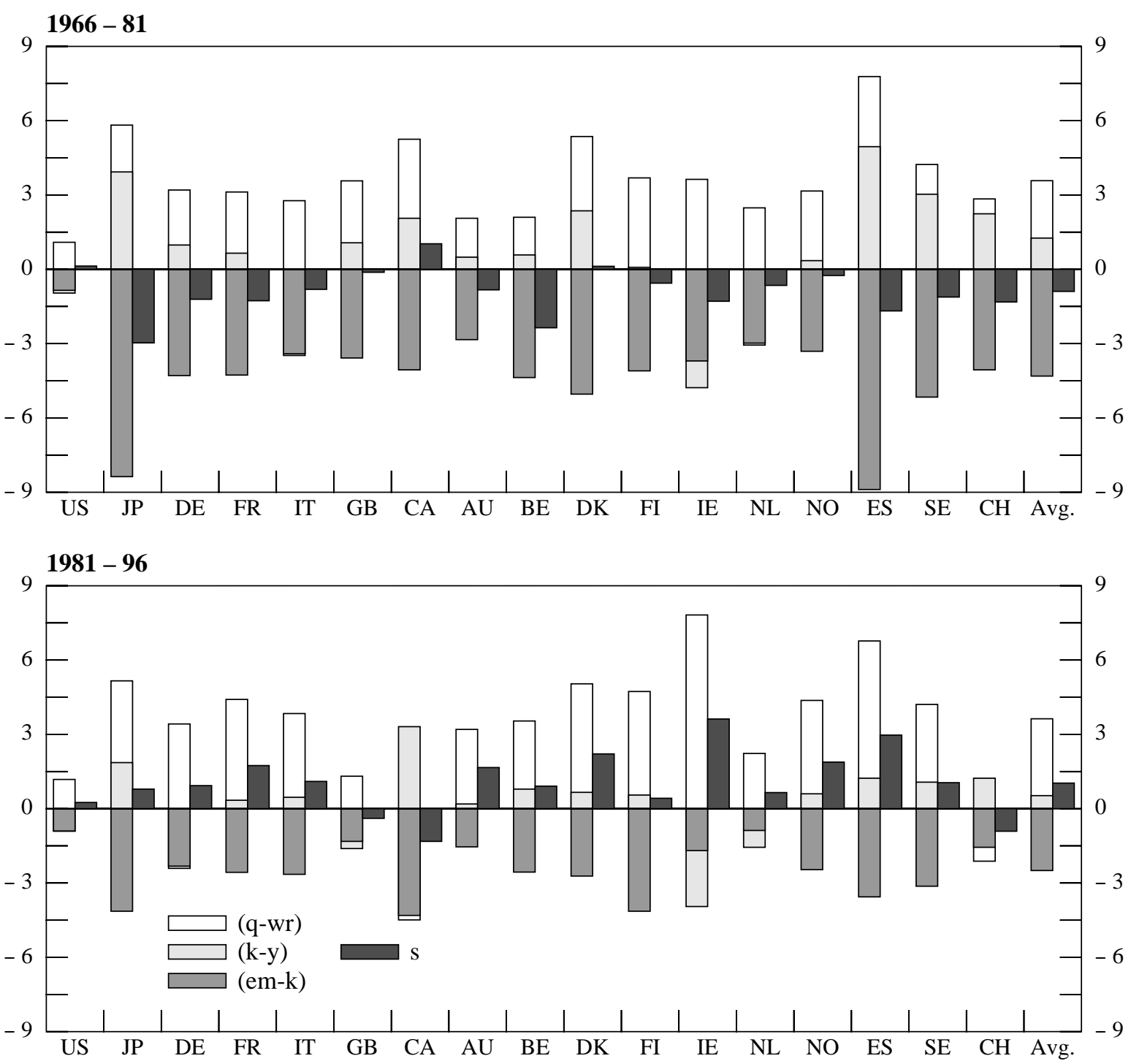

US = United States; JP = Japan; DE = Germany; FR = France $\quad$ IT = Italy; GB = United Kingdom $;$ CA = Canada; $\mathrm{AU}=$ Australia $; \mathrm{BE}=$ Belgium $; \mathrm{DK}=$ Denmark $; \mathrm{FI}=$ Finland $; \mathrm{IE}=$ Ireland $; \mathrm{NL}=$ Netherlands $; \mathrm{NO}=$ Norway; $\mathrm{ES}=$ Spain $; \mathrm{SE}=$ Sweden $; \mathrm{CH}=$ Switzerland $;$ Avg. $=$ unweighted average .

From this perspective, it appears that those countries which, ceteris paribus, suffered the largest trend declines in profit shares during 1966-81 were those which attempted to offset increases in real wages by high growth of capital per labour but did not succeed in getting a sufficiently high rate of labour productivity growth. Japan is the most extreme case, but similar developments can be observed in continental Europe. Canada also experienced a rather small productivity "return" on a strong increase in the capital/labour ratio. However, because real wage growth was relatively modest and the capital/output ratio rose sharply, the profit share increased. Denmark shows a similar picture, except

fall of $0.9 \%$. As regards the rate of return over the first period, the decline in profit shares was reinforced by the rise in capital/output ratios but attenuated by the fall in the relative price of capital goods, generating a net fall of $0.9+1.2-$ $0.1=2.0 \%$. 
that real wage growth was much higher so that, with only a modest rise in the profit share, the expansion of the capital/output ratio led to a trend decline in the rate of return. The United States recorded increases, albeit modest, in both the profit share and the rate of return. However, capital expansion played only a minor role and the capital/output ratio actually fell.

Graph 3

\section{Capital/output ratios and rates of return}

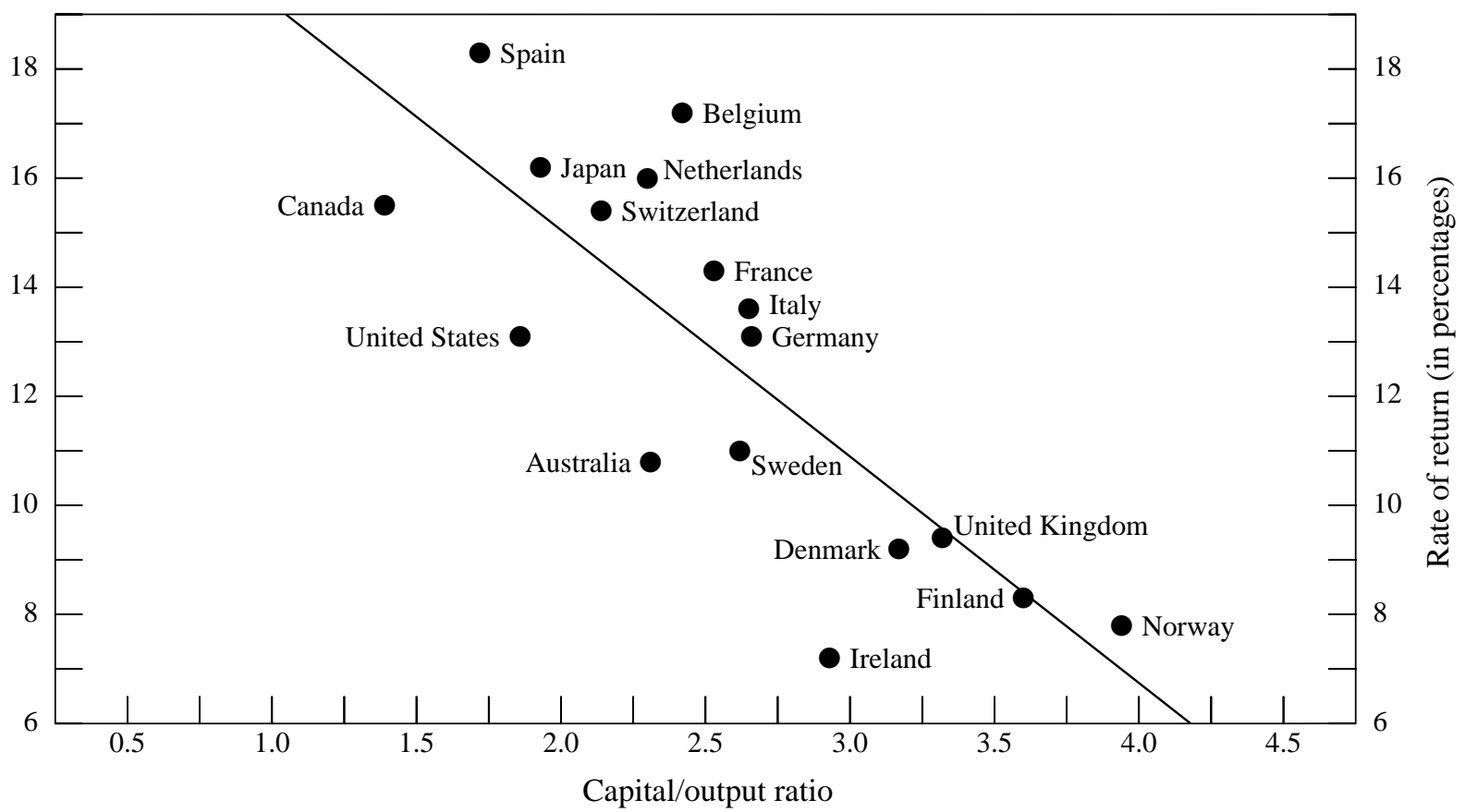

Reflecting the general slowdown in investment spending, the trend rise in capital/labour ratios slowed significantly in the second sub-period and, since the growth in real profits per person employed accelerated, the net effect of these two components imparted a positive trend $(3.1-2.5=0.6 \%$ for the seventeen countries on average) to profit shares. The slowdown in investment spending also meant that movements in capital/output ratios provided a smaller stimulus to profit shares than in the first sub-period, but helped to ease downward pressures on rates of return. Thus, with the trend decline in real capital prices accelerating, rates of return almost regained their levels of the 1960s. The continuous reduction in the capital/output ratio of Ireland is particularly notable in this respect. In the early 1980s, Ireland was close to the bottom of the capital/output curve in Graph 3 and had the lowest rate of return of all the seventeen countries. ${ }^{11}$ However, by 1996 it was near the top, while the rate of return had grown by almost $7 \%$ per year. In contrast, the capital/output ratio of Canada shows a continuous rise and, as productivity growth has failed to pick up (see the last column), the rate of return has fallen by almost $2 \%$ per year since 1981. A similar process may be observed in Switzerland,

11 The bilateral relationship between the rate of return to capital and the capital/output ratio can be derived from (i) and (iv) above as $R=(S /(K / Y))\left(P_{y} / P_{k}\right)$ and thus holds only, given profit shares and real capital goods prices. We estimated a similar cross-country relation, replacing capital/output with capital/labour ratios. The fit was about the same as for the specification used in the graph, though only after allowing for Ireland (significant "underperformance") and the Netherlands and Switzerland (significant "overperformance") as "extreme" cases. 
except that the trend fall in real capital prices has more than offset the effect of the rise in the capital/output ratio.

In the continental EU countries, the slowdown in real wage growth since 1981 has significantly raised the growth of real profits per person employed. Moreover, since capital/labour and capital/output ratios both increased at a slower rate and returns were also boosted by the accelerated rate of decline in the real price of capital goods, the profitability of European firms recovered substantially. Australia, Denmark and Sweden present very similar pictures, whereas the recovery was more modest in Norway and Finland. A main feature of US developments continued to be rather moderate changes, with lower capital goods prices the main contribution to the improvement in the rate of return.

All in all, the general slowdown in the trend growth of capital/output ratios and the fall in real capital goods prices have been favourable from the point of view of firms' rate of return. Nonetheless, and especially in continental Europe, these trends should also be seen against the background of sluggish labour demand growth and rising unemployment. Indeed, for the seventeen countries as a group, the trend decline in the real price of capital accounts for about two-thirds of the rise in rates of return, suggesting that firms have preferred to strengthen profit margins and rates of return rather than take lower capital goods prices as an opportunity to build up their capital stock. ${ }^{12}$ The contribution of changes in factor ratios and relative prices is actually largest in the United States and the United Kingdom. But, unlike in continental Europe, capital spending seems to have been sufficiently strong to support high employment growth and lower unemployment.

However, to evaluate the adequacy of firms' investment response it is necessary to analyse and understand the underlying adjustment processes.

\section{Factor substitution, relative factor prices and rates of return}

While the previous section essentially related changes in rates of return and profit shares to movements in sub-components, a more fundamental question is how firms have adjusted factor proportions in response to changes in ex ante relative factor prices and how, in turn, ex post relative factor returns have reacted to changes in factor proportions. We analyse these issues using several approaches. As a starting point, Table 3 presents trend growth rates for factor ratios and relative factor prices. As the table shows, the changes have been substantial, both for 1966-96 as a whole and for the two sub-periods. In most of the continental European countries, the growth of relative wages declined in response to the moderation of nominal wages during the second sub-period, which might, in part,

12 Since a substantial part of the real and relative fall in capital goods prices can be attributed to the steep decline in computer prices, various organisational constraints are likely to have slowed the adjustment. The gradual shift in the distribution of output and employment towards sectors with lower capital requirements may have played an additional role; see Browne and Hellerstein (1997). 
explain the slower growth of capital. Trend changes in capital/labour ratios could also have been influenced by the slowdown in European output growth and, perhaps, by shifts in elasticities of substitution. To explore these issues, Sub-section (a) presents various approaches to estimating elasticities of substitution; in Sub-section (b) we then evaluate to what extent ex post factor returns have responded to changes in factor proportions.

Table 3

Capital labour ratios and relative factor prices: trend growth rates

\begin{tabular}{|c|c|c|c|c|c|c|c|c|}
\hline \multirow[t]{2}{*}{ Countries } & \multicolumn{3}{|c|}{$\Delta($ K/Em $)$} & \multicolumn{3}{|c|}{$\Delta\left(\boldsymbol{W} / \boldsymbol{P}_{k}\right)$} & \multicolumn{2}{|c|}{ Memo: 1981-96 } \\
\hline & 1966-96 & 1966-81 & 1981-96 & 1966-96 & 1966-81 & 1981-96 & $\Delta K$ & $\Delta E m$ \\
\hline United States & 1.01 & 0.85 & 0.90 & 1.75 & 0.80 & 2.65 & 2.81 & 1.88 \\
\hline Japan & 6.09 & 8.37 & 4.14 & 5.28 & 7.43 & 2.97 & 5.55 & 1.18 \\
\hline Germany & 3.24 & 4.29 & 2.32 & 2.72 & 3.80 & 1.88 & 2.86 & 0.48 \\
\hline France & 3.47 & 4.27 & 2.57 & 2.85 & 4.00 & 1.90 & 2.56 & -0.08 \\
\hline Italy & 2.78 & 3.41 & 2.65 & 2.34 & 2.40 & 2.65 & 2.72 & -0.01 \\
\hline United Kingdom & 2.54 & 3.58 & 1.32 & 2.25 & 1.60 & 2.65 & 2.69 & 1.34 \\
\hline Canada & 4.72 & 4.06 & 4.31 & 4.41 & 2.96 & 4.43 & 5.92 & 1.36 \\
\hline Australia & 2.39 & 2.84 & 1.54 & 1.46 & 2.35 & 1.45 & 3.65 & 2.05 \\
\hline Belgium & 3.71 & 4.37 & 2.56 & 3.67 & 5.77 & 2.47 & 3.07 & 0.45 \\
\hline Denmark & 3.83 & 5.04 & 2.72 & 1.92 & 2.45 & 2.25 & 2.90 & 0.10 \\
\hline Finland & 3.83 & 4.10 & 4.14 & 3.38 & 3.23 & 3.25 & 2.26 & -1.97 \\
\hline Ireland & 3.45 & 3.70 & 1.69 & 4.41 & 3.72 & 3.36 & 2.47 & 0.75 \\
\hline Netherlands & 1.85 & 2.98 & 0.88 & 1.59 & 3.64 & 1.06 & 2.25 & 1.35 \\
\hline Norway & 3.04 & 3.31 & 2.46 & 0.99 & 1.86 & 0.80 & 2.09 & -0.42 \\
\hline Spain & 6.68 & 8.89 & 3.56 & 4.29 & 6.30 & 2.60 & 4.02 & 0.32 \\
\hline Sweden & 3.93 & 5.16 & 3.13 & 2.98 & 3.55 & 3.67 & 2.95 & -0.27 \\
\hline Switzerland & 2.49 & 4.06 & 1.56 & 3.32 & 4.72 & 3.92 & 2.89 & 1.28 \\
\hline
\end{tabular}

Notation: K/Em: capital/labour ratio; W/Pk: ratio of nominal wage to price of capital goods; $\Delta$ : first-difference operator.

(a) Elasticities of substitution: various approaches

As a first approach, we estimated elasticities of substitution directly from the aggregate two-factor CES production function:

$$
Y=C\left((1-\alpha) K^{\beta}+\alpha E m^{\beta}\right)^{1 / \beta}
$$

where $Y$ denotes output, $K$ the capital stock and $E m$ labour input, while the elasticity of substitution $(\sigma)$ can be derived as $1 /(1-\beta) .{ }^{13}$ The resulting technical elasticities of substitution are shown in Table 4 as $\sigma_{1}$.

13 The non-linear form does not lend itself easily to estimation and to obtain values for $\beta$ we developed a Newtonian algorithm which minimised the squared sum of residuals between the left-hand side observations and the right-hand side values as generated by iterations on the three parameters $C, \alpha$ and $\beta$. Two caveats are, however, in order here. First, the CES function in (i) disregards technical progress in the sense that when (i) is used in the cost minimising equations below, it is implicitly assumed that technical progress is of the Hicksian type. Second, it would probably have been more 
As a second approach, we assumed that firms choose factor inputs with a view to minimising production costs. Using again the CES production function in (i), the minimum cost condition requires that the ratio of marginal productivities equals the ratio of factor prices:

$$
Y^{\prime}{ }_{K} / Y^{\prime}{ }_{E m}=U C / W
$$

where $W$ is compensation per employee and $U C$ the user cost of capital. As a first approximation, we used the price of capital goods $\left(P_{K}\right)$ as a proxy for $U C$ even though capital costs, inter alia, also depend on the costs of debt financing, equity prices, tax rates and the tax rules applying to depreciation and debt interest payments. However, because investment is mostly financed out of retained earnings and firms appear to pay little attention to opportunity costs, we have left further discussion of the potential influence of interest rates and the shift to positive real interest rates in the 1980s to the next sub-section. ${ }^{14}$ Since:

$$
Y^{\prime}{ }_{K}=(1-\alpha) C\left((1-\alpha) K^{\beta}+\alpha E m^{\beta}\right)^{(1-\beta) / \beta} K^{\beta-1}
$$

and an analogous expression can be derived for $E m$, the factor price ratio must satisfy:

$$
P_{K} / W=((1-\alpha) / \alpha)(K / E m)^{\beta-1}
$$

which leads to the cost-minimisation condition:

$$
\left.K / E m=(\alpha /(1-\alpha)) P_{K} / W\right)^{1 /(\beta-1)}=a_{o}\left(W / P_{K}\right)^{\sigma}
$$

since $\sigma=1 /(1-\beta)$. By taking logs, we then get the following equation for estimating $\sigma$ :

$$
\log (K / E m)=\log a_{o}+\sigma \log \left(W / P_{K}\right)
$$

Applying ordinary least squares to (vi) produces the substitution elasticities shown as $\sigma_{2}$ in Table 4 , while the same equation in first differences yields the elasticities shown as $\sigma_{3 .}{ }^{15}$

satisfactory to estimate (i) using a non-linear regression package, which would have enabled us to formally test the hypothesis that the estimated $\sigma$ 's differ significantly from unity. However, in defence of our procedure we note that it produced excellent tracking abilities and seventeen out of seventeen $\sigma$ ‘s that all exceeded unity.

14

In an attempt to extend $U C$ to include interest costs, we initially estimated (vi) as:

$\log (K / E m)=\log a_{o}+\sigma \log \left(W / P_{k}\right)+\sigma \eta \log I R L+\varepsilon$

where $I R L$ denotes the long-term borrowing rate and $\eta$ (positive and $\leq 1$ ) is included to capture the extent to which firms rely on external financing and/or pay attention to opportunity costs. However, in most cases, $\sigma \eta$ obtained the wrong sign or was insignificant. Moreover, in those cases where a significant negative coefficient was obtained, the implied value of $\eta$ was less than 0.10 .

15 We also estimated equation (vi) on panel data (variable intercept terms) for the seventeen countries (459 observations), obtaining the following results for variables in respectively levels and first differences (t-ratios in brackets):

\begin{tabular}{|l|l|l|l|l|}
\hline & \multicolumn{1}{|c|}{$\sigma$} & $\mathrm{R}^{2}$ & St.e & $\mathrm{DW}$ \\
\cline { 2 - 5 } Levels & $1.12(51.2)$ & 0.97 & 0.10 & 0.12 \\
First differences & $0.26(7.1)$ & 0.26 & 0.02 & 1.02 \\
\hline
\end{tabular}


As a third approach, we attempted to correct for cyclical fluctuations by introducing the simplifying assumption that both the $K / E m$ and the $W / P_{K}$ ratios trace exponential trends; i.e.:

$$
\begin{aligned}
& K / E m=k_{o} e^{b t} \\
& W / P_{K}=f_{o} e^{c t}
\end{aligned}
$$

By inserting into (vi), we then have:

$$
\log k_{o}+b t=\log a_{o}+\sigma \log f_{0}+\sigma c t
$$

from which $\sigma$ can be derived from estimates of $b$ and $c$ as $\sigma=b / c$. The corresponding elasticities are shown as $\sigma_{4}$ in Table 4, first for the whole period 1966-96 and then for the two sub-periods.

Table 4

Alternative elasticities of substitution

\begin{tabular}{l|c|c|c|c|c|c}
\hline \multirow{2}{*}{ Countries } & \multicolumn{2}{|c|}{$\mathbf{1 9 6 6 - 9 6}$} & \multicolumn{2}{c|}{$\mathbf{1 9 6 6 - 8 1}$} & \multicolumn{2}{c}{$\mathbf{1 9 8 1 - 9 6}$} \\
\cline { 2 - 7 } & $\sigma_{\mathbf{1}}$ & $\sigma_{\mathbf{2}}$ & $\sigma_{\mathbf{3}}$ & $\sigma_{\mathbf{4}}$ & $\sigma_{\mathbf{4}}$ & $\sigma_{\mathbf{4}}$ \\
\hline United States & 1.37 & 0.53 & 0.10 & 0.58 & 0.98 & 0.33 \\
Japan & 1.09 & 1.14 & 0.97 & 1.15 & 1.08 & 1.26 \\
Germany & 1.50 & 1.16 & 0.84 & 1.19 & 1.06 & 0.96 \\
France & 1.34 & 1.17 & 0.66 & 1.22 & 1.00 & 1.23 \\
Italy & 1.41 & 1.14 & 0.35 & 1.19 & 1.42 & 0.99 \\
United Kingdom & 1.35 & 1.08 & 0.62 & 1.13 & 2.33 & 0.47 \\
Canada & 1.33 & 1.04 & 0.72 & 1.07 & 1.41 & 0.99 \\
Australia & 1.35 & 1.45 & 0.48 & 1.64 & 1.22 & 1.41 \\
Belgium & 1.71 & 0.97 & 0.69 & 1.01 & 0.77 & 1.08 \\
Denmark & 1.40 & 1.93 & 0.95 & 1.99 & 2.12 & 1.28 \\
Finland & 2.11 & 1.13 & 0.69 & 1.13 & 1.28 & 1.23 \\
Ireland & 1.34 & 0.82 & 0.48 & 0.78 & 0.91 & 0.45 \\
Netherlands & 1.32 & 1.01 & 0.52 & 1.16 & 0.82 & 0.79 \\
Norway & 1.48 & 2.36 & 0.49 & 3.07 & 2.07 & 2.29 \\
Spain & 1.62 & 1.49 & 1.09 & 1.51 & 1.37 & 1.47 \\
Sweden & 1.32 & 1.28 & 0.70 & 1.32 & 1.43 & 0.88 \\
Switzerland & 1.31 & 0.76 & 0.53 & 0.75 & 0.98 & 0.46 \\
\hline Average* & 1.45 & 1.20 & 0.64 & 1.30 & 1.31 & 1.03 \\
\hline * Unweighted. & & & & & & \\
\hline
\end{tabular}

Overall, the directly estimated technical elasticities $\left(\sigma_{1}\right)$ tend to exceed those obtained using the cost minimisation assumption $\left(\sigma_{2}\right)$ and the range across countries is also much narrower than for $\sigma_{2}$. The elasticities obtained using the "short-cut method" $\left(\sigma_{4}\right)$ are broadly consistent with $\sigma_{1}$ and $\sigma_{2}$ but this consistency masks rather large changes between the sub-periods. On average for the seventeen countries, $\sigma_{4}$ has declined from 1.3 to 1.0 from the first to the second sub-period, with particularly large falls observed for the English-speaking countries (except Australia), Italy, Denmark, Sweden and Switzerland. Other European countries offer a rather mixed picture, while the elasticity appears to 
have increased in Japan. However, in evaluating these results it is important to take account of the large variations across countries in changes in employment and capital. For instance, the rise in capital/labour ratios in continental Europe has mostly been generated through very low or negative rates of employment growth (Table 3, last column), while in the English-speaking countries both labour and capital inputs have increased. Hence, when estimating substitution elasticities on the assumption that all shifts originate on the supply side and ignoring policy-induced and other shifts in the demand for labour, there is a risk that the elasticity estimates will be biased.

It is also notable that while the elasticities obtained from variables in levels are broadly similar and, for most countries, close to or above unity, those obtained from variables in first differences $\left(\sigma_{3}\right)$ are significantly smaller and, for about half the countries, well below unity. This suggests that even though the substitution elasticities obtained from equations based on variables in levels are in line with consensus estimates, such equations are misspecified because the adjustment of factor ratios to changes in relative factor prices is not instantaneous. As a result, the sample period mostly contains observations from transitional movements between equilibria. This has two implications. ${ }^{16}$ First, an error correction model with variables in levels as well as first differences would be a more appropriate estimation procedure. Second, if the adjustment of factor proportions is subject to lags, ex post changes in factor shares of income and relative returns will differ from those predicted by the long-run elasticities of substitution. ${ }^{17}$ Hence, the surprisingly strong rise in profit shares and rates of return discussed in Section 2 might, to a large extent, be attributable to the lags in the adjustment process. In the following we attempt to implement models which capture both features and, in this context, we also introduce additional approaches to estimating elasticities of substitution. ${ }^{18}$

\section{Changes in factor proportions and ex post relative returns}

To estimate and identify the lags in the adjustment of factor ratios and factor returns, we adopted a three-step procedure.

16 A third implication, or possibility, would be that the aggregate production function with homogeneous inputs is invalid and that a putty-clay production structure would have been more appropriate. However, while we fully agree with Caballero and Hammour (1998) that the low supply elasticity of capital already installed is a key factor in explaining the fall in profit shares during 1966-81, we preferred a more ad hoc approach which, while allowing for adjustment lags, enabled us to test other potential determinants.

17 For instance, if changes in relative factor prices induce firms to substitute capital for labour, one would expect the return to capital to decline relative to the return to labour. However, if the substitution process is subject to long lags, the ex post relative return to capital might actually rise.

The differences between the two sub-periods could also be suggestive of shifts in the behaviour of firms. For instance, during 1966-81, firms probably increased their capital/labour ratios as a defensive response to the rise in real wages; in contrast, over the next fifteen years, the increase in capital/labour ratios seems to have been mainly driven by the development in capital goods prices and demand-side-induced lower output growth rates. while wage moderation helped to boost the return to capital. 
First, we estimated equation (vi) as an error correction model and then used the predicted factor ratios as instrumental variables in steps two and three. Details of the estimates are given in Annex Table A1, while the implied elasticities of substitution and speeds of adjustment are shown in Table 6 below as $\sigma_{5}$ and $\gamma_{1}$

Second, to quantify the influence of adjustment lags on ex post factor shares, we went back to equation (iv) and replaced $P_{k}$ with $\mu$, which may be interpreted as a measure of the return to capital or "revealed user cost":

$$
\mu / W=((1-\alpha) / \alpha)(K / E m)^{\beta-1}
$$

Multiplying both sides of (iv)' by $K / E m$ then gives:

$$
\text { (iv) }, \quad \mu K / W E m=((1-\alpha) / \alpha)(K / E m)^{\beta}
$$

The left-hand side can be interpreted as a measure of the ex post distribution of factor income, since the numerator equals total profits while the denominator is the wage sum. As our second step, we estimated (iv)" using an error correction model. The results are presented in Annex Table A2, while the implied elasticities of substitution and speeds of adjustment are shown in Table 6 as $\sigma_{6}$ and $\gamma_{2}{ }^{19}$

As our third step, we again started from equation (iv)' but used $\mu / W$ as a measure of ex post relative returns per unit of input as the left-hand variable. ${ }^{20}$ This ratio was also estimated using an error correction model, with the detailed results shown in Annex Table A3 and the implied elasticities of substitution $\left(\sigma_{7}\right)$ and speeds of adjustment $\left(\gamma_{3}\right)$ given in Table $6 .{ }^{21}$

Before turning to the estimates, it may be useful to briefly look at the actual developments in relative factor shares of income and relative rates of return as shown in Table 5 and Graphs 4a-d. Given the definition of $\mu / W$ in (iv)' and the marked rise in capital/labour ratios, we would expect the ex post relative return to capital to have declined sharply when $0<\beta<1$ or, equivalently, $\sigma>1$. As can be seen from the graph, this was indeed the case during the sub-period 1966-81, as firms substituted capital for labour in response to the rise in real wages. However, since the early 1980s, the relative return to capital has fallen much less than predicted by equation (iv)' (Table 5, columns 4 and 5), even though the substitution of capital for labour continued, albeit at a slower pace than in the 1960s and

19 Since the elasticity of substitution, $\sigma$, equals $1 /(1-\beta)$, the exponent of $(K / E m)$ in (iv)" 'can also be written as $(\sigma-1) / \sigma$, from which it is easy to derive an implied value for $\sigma$. For details, see Annex Table A2.

20 More precisely, we defined $\mu / W$ as the ratio between the real return per unit of capital and the real return per unit of labour, with the latter approximated by the real wage. In practice, we derived the left-hand side as $\left(\operatorname{Return} / P_{y}\right) / W R=$ Return/ $\left(W / P_{k}\right)$ since Return is defined as Profits/KP $P_{k}$.

21

Given the definition of $\sigma$, the elasticity of substitution for this approach can be derived from $\beta-1=-1 / \sigma_{7}$. Note that (iv)' and (iv)" 'basically tell the same story, so that the transition from (iv)' to (vi)' and the associated estimates mainly involve a change in the stochastic assumptions. 
1970s. In fact, for about one-half of the countries, the relative rate of return to capital was actually higher in 1996 than fifteen years earlier, in particular in Ireland, Denmark and Spain.

Table 5

Actual and predicted changes in relative rates of return

1981-96, in percentages

\begin{tabular}{l|r|r|r|r|r|r}
\hline \multirow{2}{*}{ Countries } & \multicolumn{3}{|c|}{ Factor shares $^{-}$} & \multicolumn{3}{c}{ Relative returns $^{\mathbf{1}}$} \\
\cline { 2 - 8 } & Actual & Predicted $^{\mathbf{1}}$ & Predicted $^{2}$ & Actual & Predicted $^{\mathbf{1}}$ & Predicted $^{\mathbf{2}}$ \\
\hline United States & 7.8 & 5.4 & 7.5 & -10.9 & -14.7 & -11.3 \\
Japan & 20.5 & 7.8 & 15.0 & -35.0 & -86.3 & -38.1 \\
Germany & 46.1 & 6.2 & 40.5 & -5.5 & -12.5 & -8.6 \\
France & 50.4 & 12.5 & 52.2 & 1.8 & -35.5 & 0.4 \\
Italy & 40.8 & 12.0 & 40.5 & -5.0 & -35.4 & -7.7 \\
United Kingdom & 13.4 & 5.0 & 5.1 & -4.9 & -13.8 & -11.3 \\
Canada & -16.0 & 23.3 & -15.3 & -57.1 & -72.7 & -59.7 \\
Australia & 24.0 & 5.5 & 24.6 & 2.5 & -15.9 & 3.0 \\
Belgium & 39.8 & 14.2 & 35.5 & -7.3 & -26.6 & -11.3 \\
Denmark & 69.2 & 12.5 & 65.7 & 16.5 & -31.5 & 12.6 \\
Finland & 32.2 & 36.1 & 29.3 & -21.7 & -40.4 & -22.9 \\
Ireland & 126.6 & 7.8 & 131.6 & 72.8 & -23.7 & 68.2 \\
Netherlands & 28.3 & 8.0 & 29.0 & 7.7 & -23.5 & 7.3 \\
Norway & 45.2 & 10.5 & 40.5 & 1.9 & -22.5 & -3.9 \\
Spain & 88.4 & 26.1 & 87.8 & 8.2 & -42.7 & 4.1 \\
Sweden & 103.2 & 38.2 & 129.3 & 3.1 & -43.2 & 17.3 \\
Switzerland & -23.7 & 6.2 & -20.5 & -43.0 & -19.8 & -43.0 \\
\hline
\end{tabular}

${ }^{1}$ Obtained by multiplying the change in $K / E m$ (in logs) by $\left(\sigma_{1}-1\right) / \sigma_{1}$ and $-1 / \sigma_{1}$, respectively, with $\sigma_{1}$ denoting the technical elasticities of substitution in Table 4. ${ }^{2}$ Obtained from the estimated equations presented in Annex Tables A2 and A3.

As regards the ratio of factor incomes as defined in equation (iv)", a rise in the capital/labour ratio can, ceteris paribus, be expected to raise profits relative to wages, as long as the elasticity of substitution exceeds unity; i.e. $\beta>0$. As can be seen from the first two columns of Table 5 , the actual increases in profits have, for most countries, exceeded those predicted by applying the technical substitution elasticities $\left(\sigma_{1}\right)$ to the actual changes in capital/labour ratios. This is consistent with the aforementioned changes in ex post returns and with the developments in profit shares discussed in Section 2. Note, however, that during 1966-81, when the rise in capital/labour ratios was much more pronounced, profits tended to fall relative to wages. This confirms the point made by Caballero and Hammour, op cit, that the short-run supply curve of capital is very steep and, more generally, that elasticities of substitution, estimated assuming full adjustment, have only limited applicability to shorter periods when economies are likely to be moving from one equilibrium to another. 
Graph 4a

Ex post rates of return and income shares

Germany
France
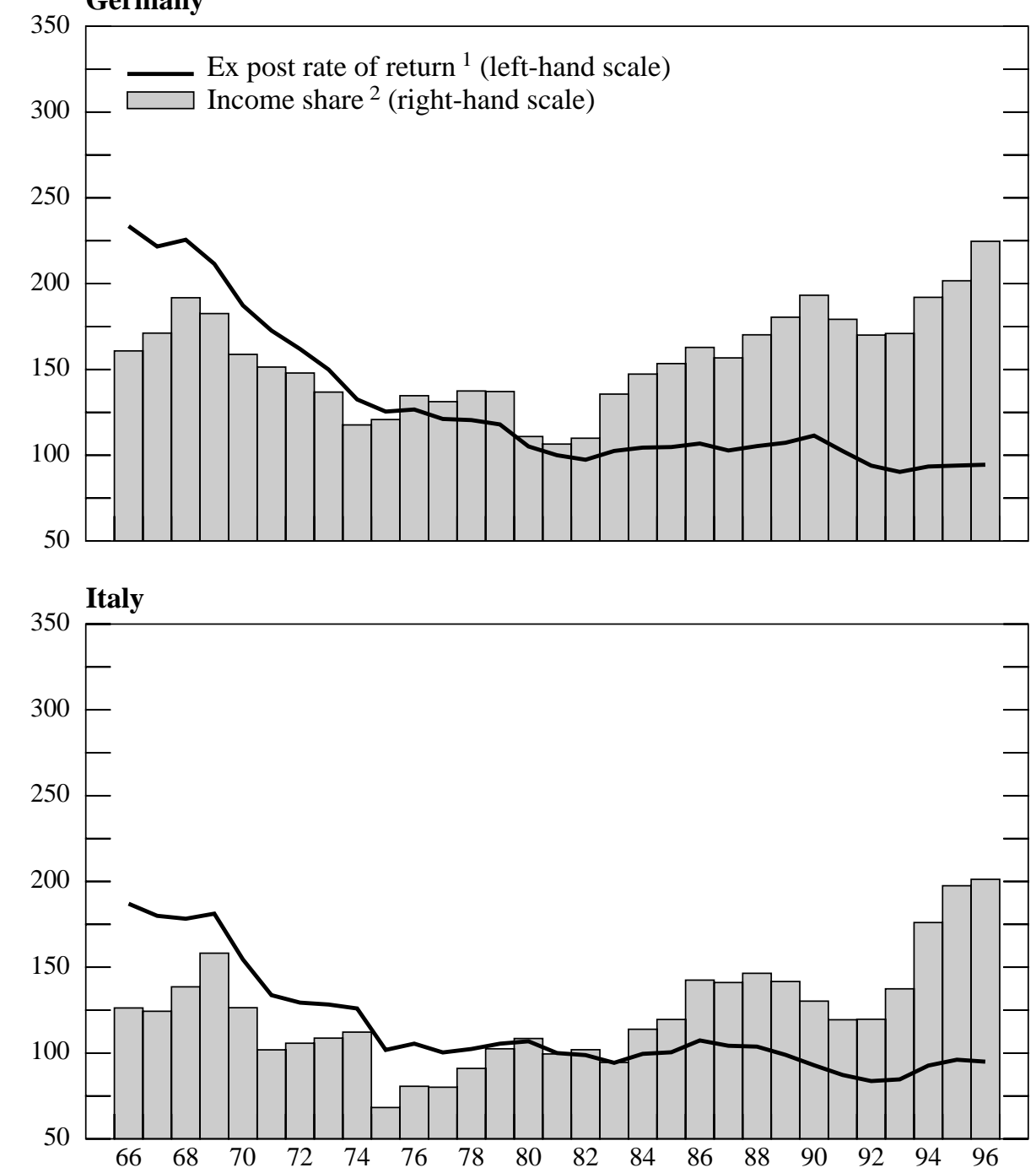

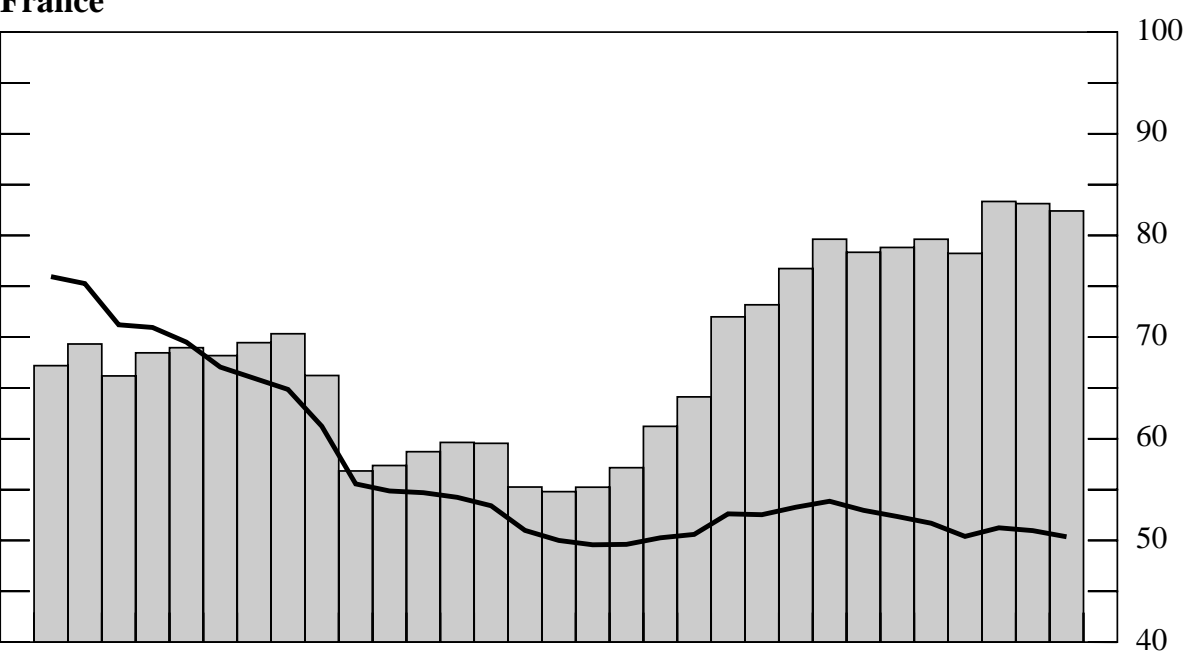

Belgium

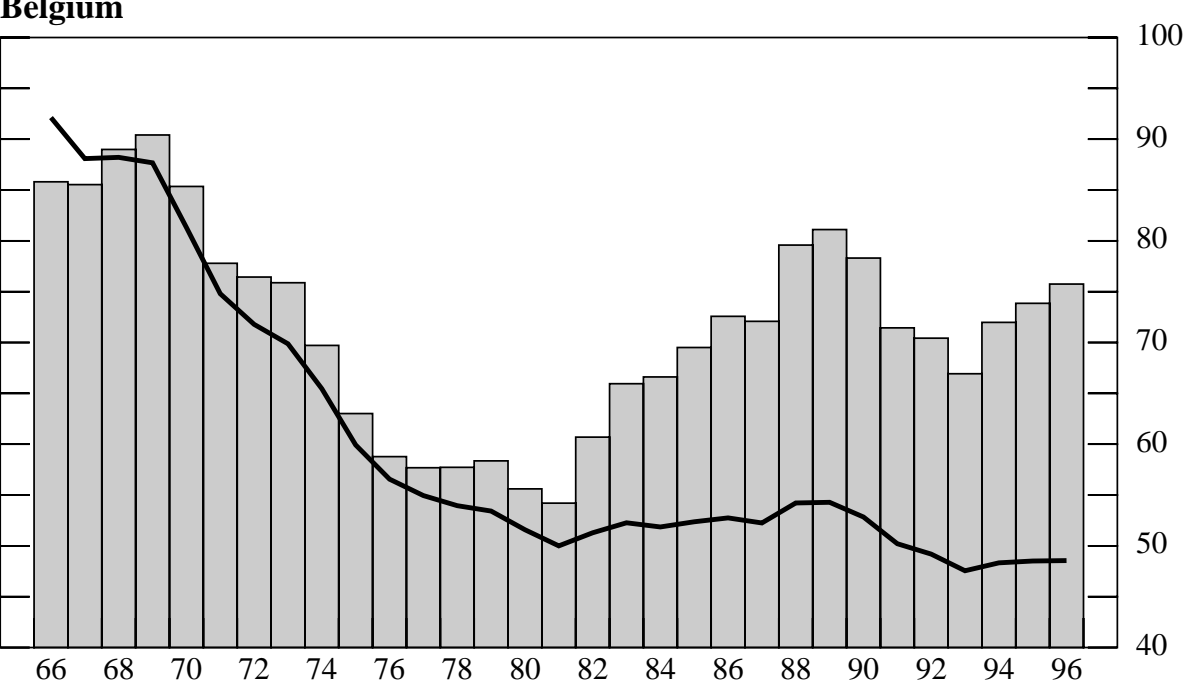

${ }^{1}$ Defined as the ratio of the real return per unit of capital to real compensation per employee; indices, $1981=100 . \quad{ }^{2}$ Defined as profits relative to total wages, in percentages. 
Graph $4 b$

Ex post rates of return and income shares

Sweden

\section{Finland}
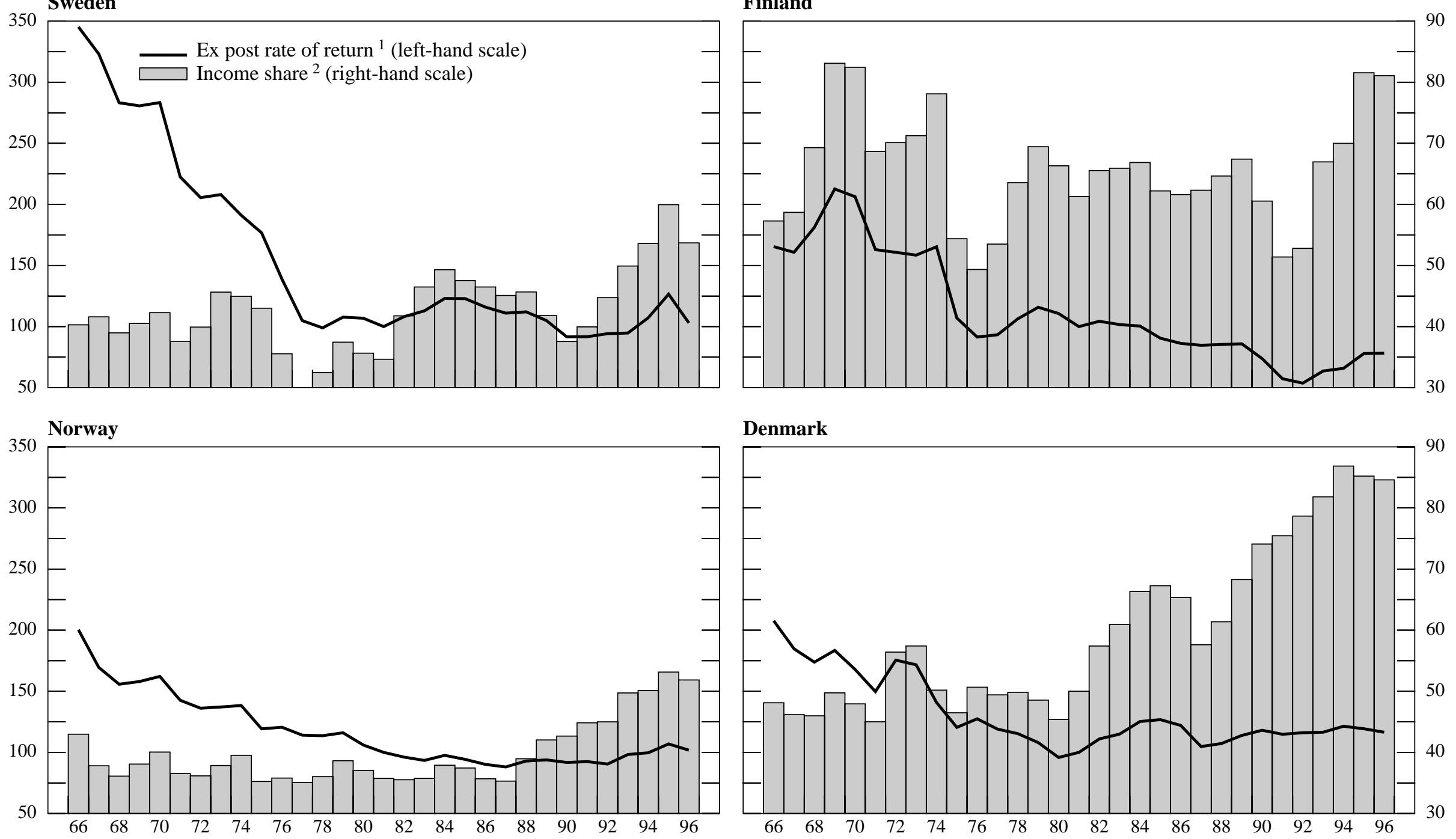

${ }^{1}$ Defined as the ratio of the real return per unit of capital to real compensation per employee; indices, $1981=100 . \quad{ }^{2}$ Defined as profits relative to total wages, in percentages. 
Graph 4c

Ex post rates of return and income shares

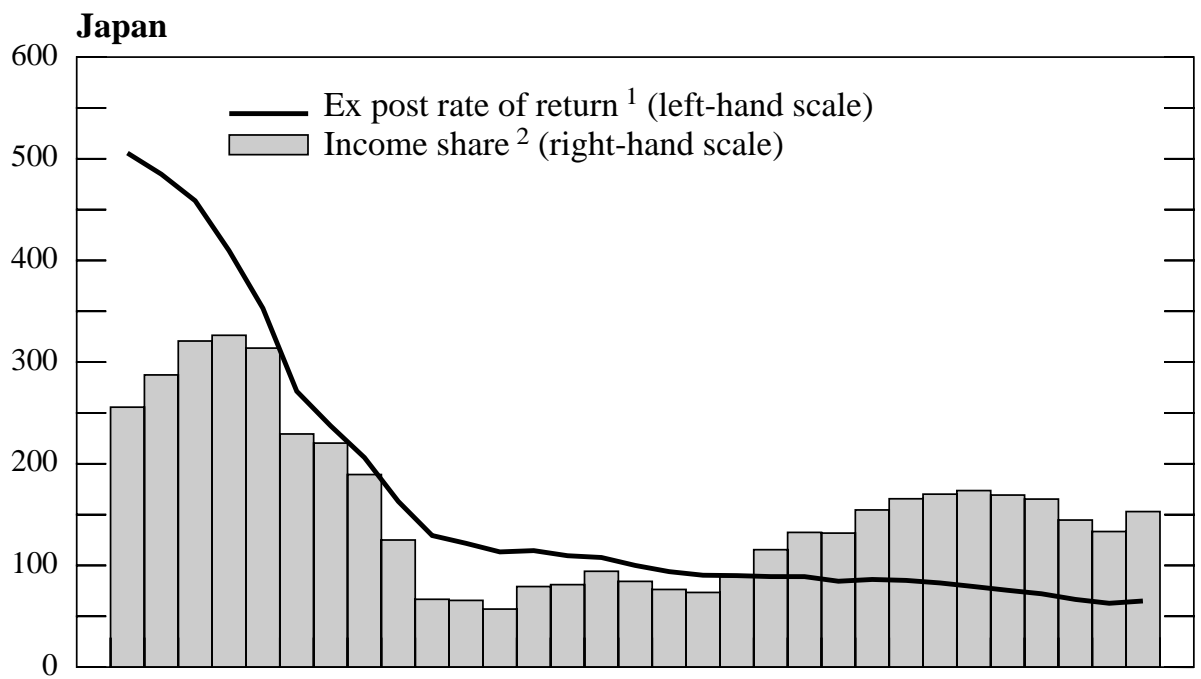

Spain

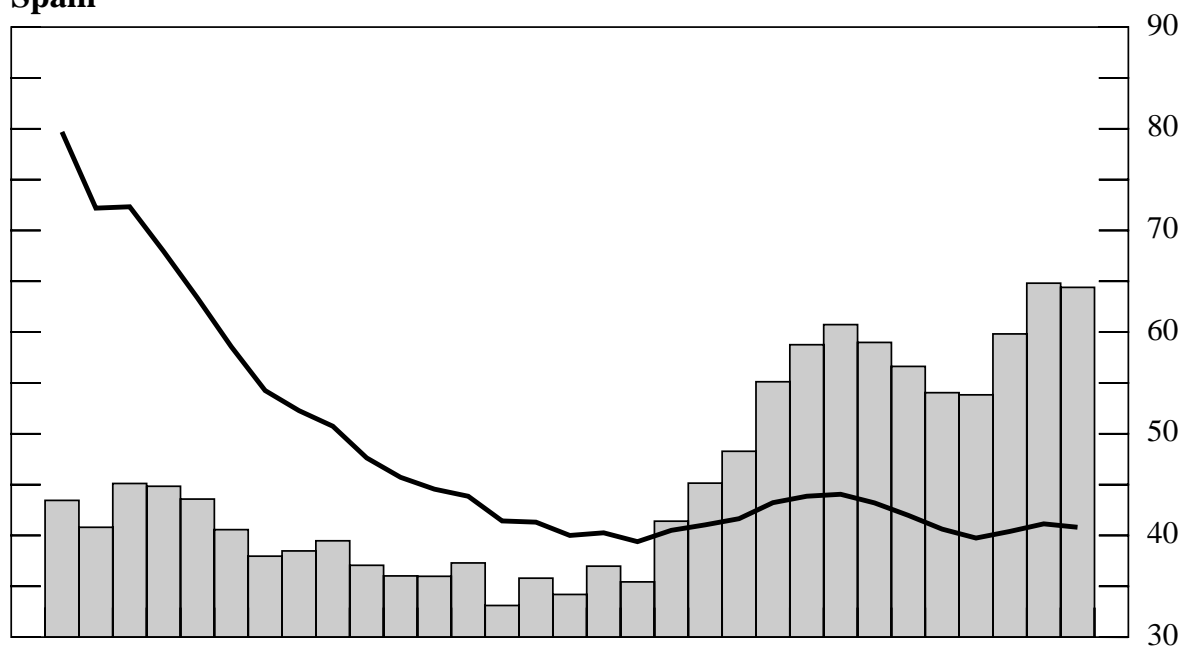

Ireland

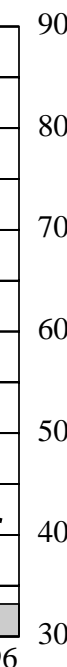

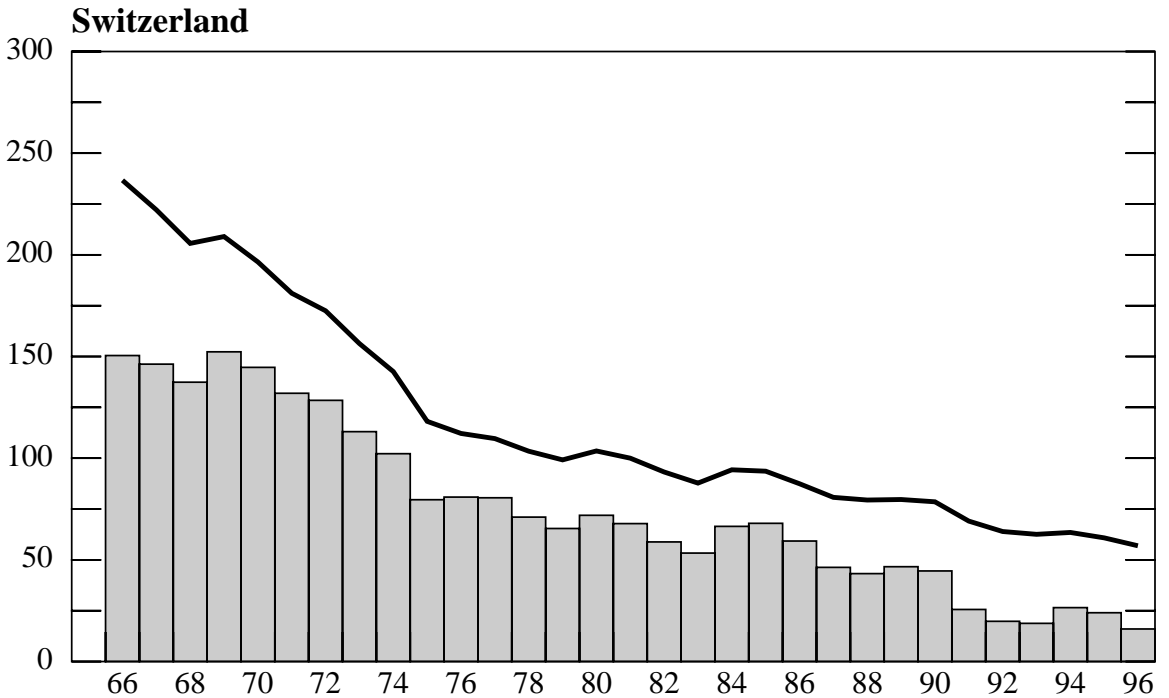

140 140

${ }^{1}$ Defined as the ratio of the real return per unit of capital to real compensation per employee; indices, $1981=100 . \quad{ }^{2}$ Defined as profits relative to total wages, in percentages. 
Graph 4d

Ex post rates of return and income shares

United States
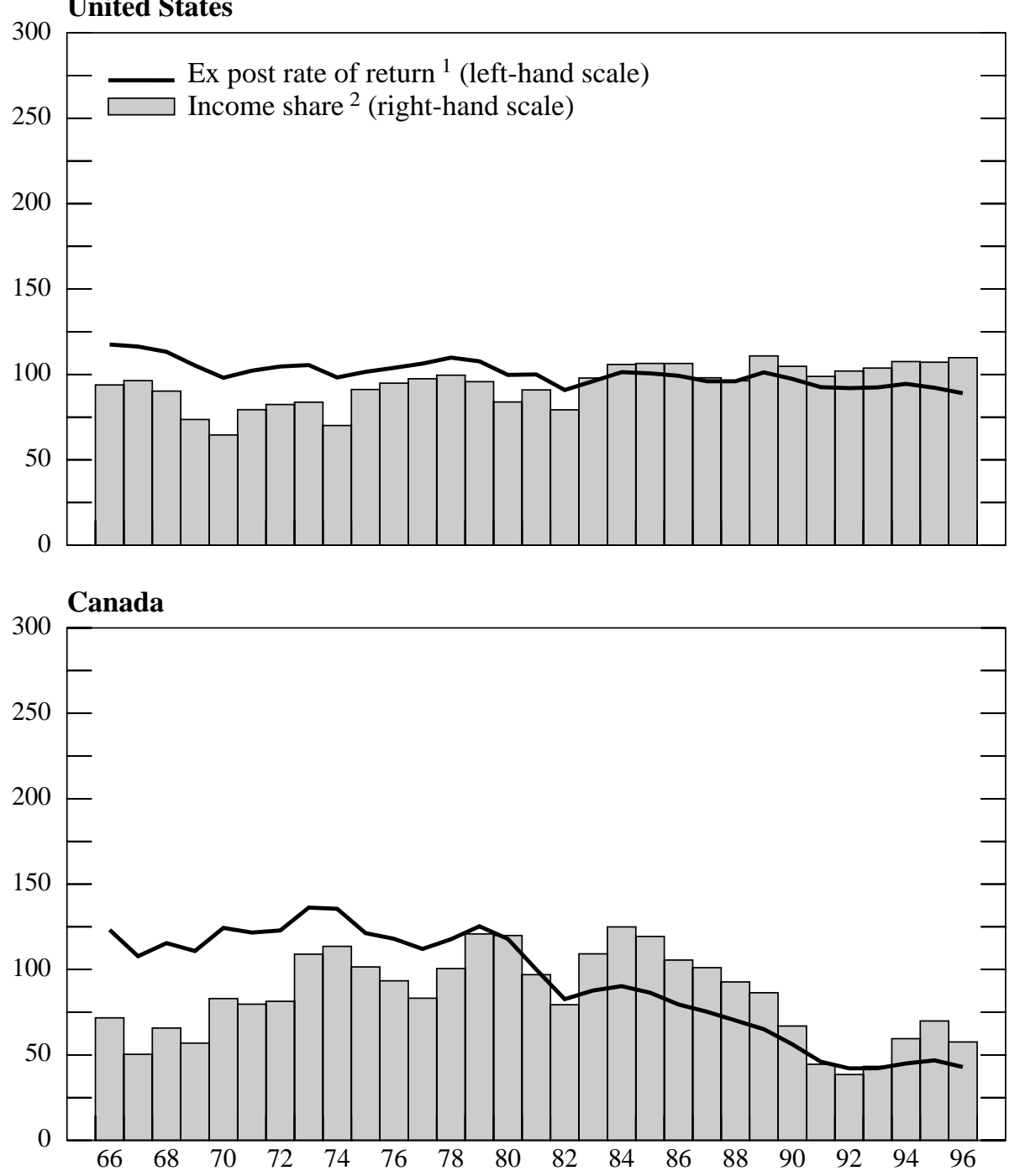

United Kingdom

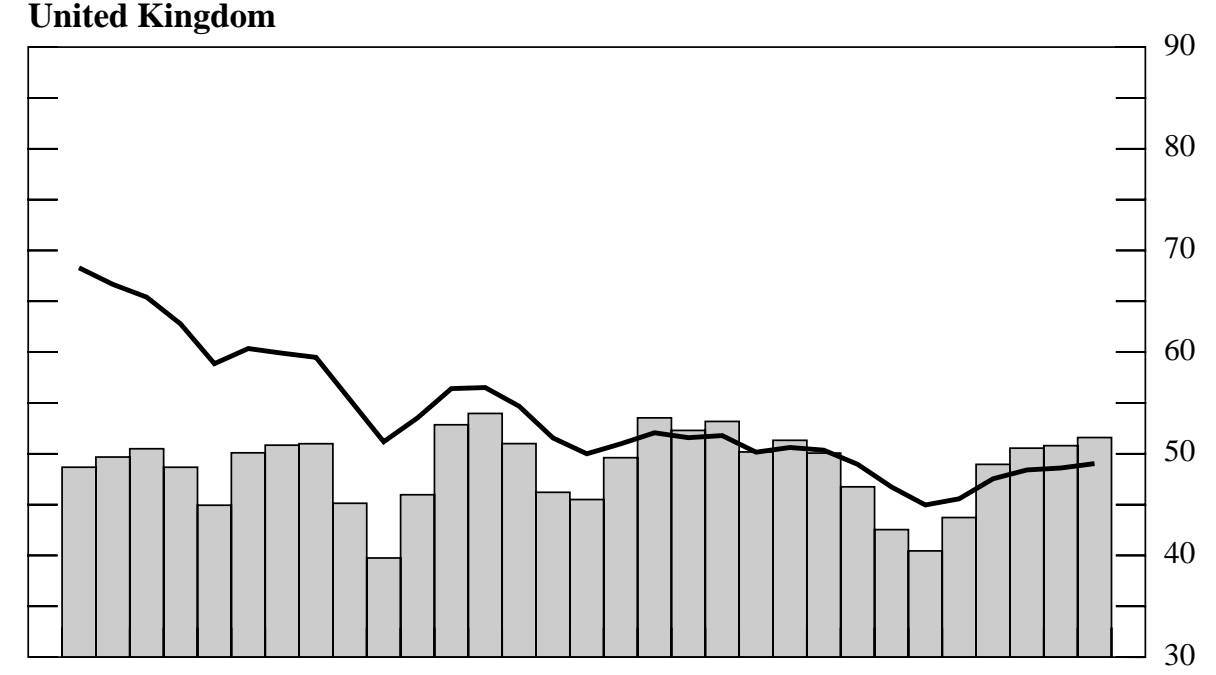

Australia

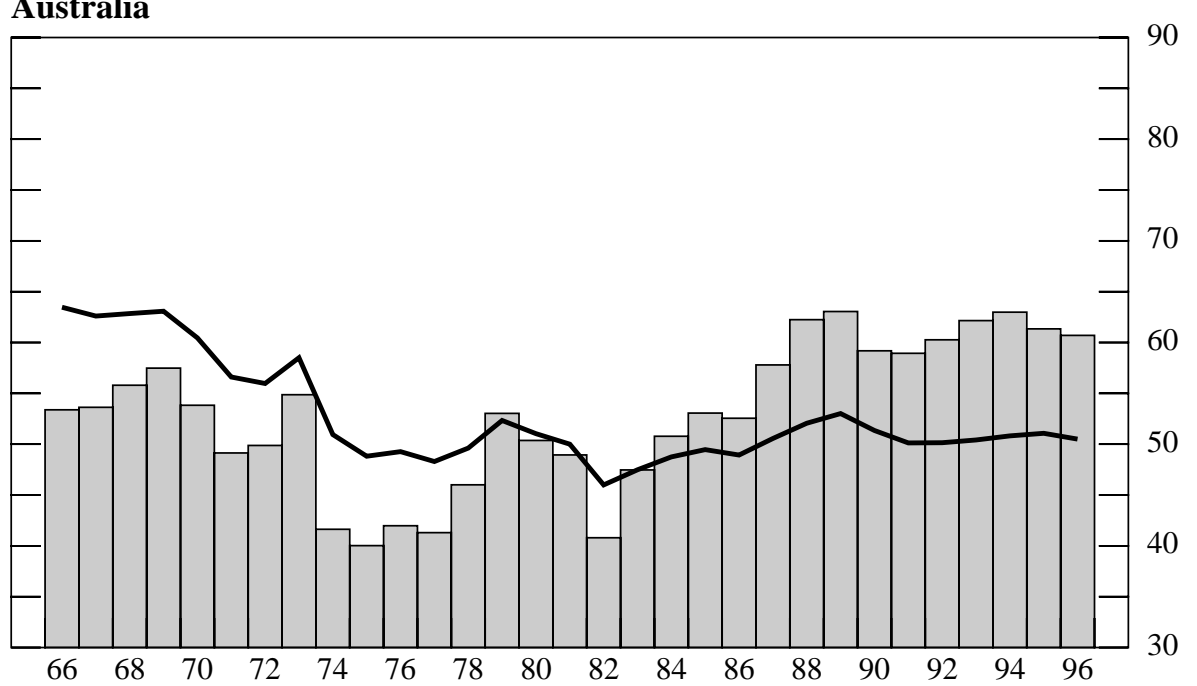

${ }^{1}$ Defined as the ratio of the real return per unit of capital to real compensation per employee; indices, $1981=100 . \quad{ }^{2}$ Defined as profits relative to total wages, in percentages. 
As noted earlier, we attempted to identify the influence of adjustment lags and other factors by estimating three error correction models with the following specifications:

$\Delta(k-e m)=\beta(k-e m)_{-1}+\varphi\left(w-p_{k}\right)_{-1}+\lambda \Delta y_{-i}+\phi \Delta\left(w-p_{k}\right)_{-i}+\rho \Delta(k-e m)_{-i}+\varepsilon$,

$\Delta \log (\pi / e m w)=\alpha+\beta \log (k / e m)_{-1}^{*}+\varphi \log (\pi / e m w)_{-1}+\lambda \Delta y_{-i}+\phi \log U_{-i}+\varphi r$ int $_{-i}+\rho \Delta \log (k / e m)_{-1}^{*}+\varepsilon$

$\Delta \log (r r)=\alpha+\beta \log (k / e m)_{-1}^{*}+\varphi \log (r r)_{-1}+\lambda \Delta y_{-1}+\phi \log U_{-i}+\varphi r i n t_{-i}+\rho \Delta \log (k / e m)_{-1}^{*}+\Delta \log \left(p_{k}-w\right)_{-i}+\varepsilon$

with $k-e m=$ capital/labour ratio, $w-p_{k},=$ relative factor prices, $\Delta y=$ rate of output growth, $\pi=$ profits, $e m w=$ wage sum, $k / \mathrm{em}^{*}=$ estimated capital/labour ratio, $U=$ rate of unemployment, rint $=$ real rate of interest, and $r r=$ real rate of return per unit of capital/real product wage. $\Delta$ is the first-difference operator and each equation also includes a random error.

The first equation is a straightforward transformation of the earlier equation (vi) and only adds output changes as an additional variable. The equations for respectively factor shares and factor returns also allow for shifts in the distribution of rents by introducing the rate of unemployment as a measure of relative bargaining strength. Moreover, on the assumption that higher real interest rates might give firms an incentive to raise profit margins ${ }^{22}$ and that profits tend to be more procyclical than wages, real long-term interest rates and rates of output growth were included as well. ${ }^{23}$

The results for the factor adjustment equation reveal several interesting features (see Annex Table A1). First, the adjustment process contains a significant cyclical component, as slow (fast) growth tends to induce a faster (slower) change of factor ratios. Second, the implied elasticities of substitution $\left(\sigma_{5}\right.$ in Table 6$)$ are only about half as large as those found earlier. Third, the speed of adjustment is extremely low as, for most countries, less than $10 \%$ of the gap between the actual and the desired capital/labour ratio is closed within one year. Although for some countries the parameters are not as precisely estimated as we would have liked, the long lags, combined with the relatively low elasticities of substitution, seem to suggest that the underlying production function is 'putty-clay', rather than 'putty-putty' as implicitly assumed in equations (i)-(iv).

22 It is debatable whether movements in real interest rates act as an independent factor or affect factor returns via changes in the rate of unemployment. See Phelps (1994) on the role of real interest rates in explaining developments in European unemployment and Nickell (1998) for evidence of real interest rate effects on UK unemployment. It should also be recalled that one shortcoming of the data used in this paper is that we cannot distinguish between profits for, respectively, financial and non-financial enterprises, so that net interest payments and receipts cancel out. However, the hypothesis would still hold if non-financial firms reacted to higher real interest rates, whereas financial institutions did not. 
Table 6

Elasticities of substitution $(\sigma)$ and speeds of adjustment $(\gamma)$ Error correction equations*

\begin{tabular}{l|c|c|c|c|c|c}
\hline Countries & $\sigma_{5}$ & $\gamma_{1}$ & $\sigma_{6}$ & $\gamma_{2}$ & $\sigma_{7}$ & $\gamma_{3}$ \\
\hline United States & 0.56 & 0.077 & 1.88 & 0.617 & 3.20 & 0.434 \\
Japan & 0.65 & 0.034 & 1.40 & 0.167 & 1.60 & 0.240 \\
Germany & 0.78 & 0.053 & 0.53 & 0.193 & 0.77 & 0.344 \\
France & 0.52 & 0.075 & 1.35 & 0.250 & 1.05 & 0.181 \\
Italy & 0.65 & 0.089 & 2.28 & 0.251 & 1.00 & 0.406 \\
United Kingdom & 0.48 & 0.079 & 0.72 & 0.897 & 1.34 & 0.395 \\
Canada & 0.64 & 0.081 & 0.69 & 0.381 & 0.74 & 0.357 \\
Australia & 0.63 & 0.101 & 1.80 & 0.255 & 1.60 & 0.400 \\
Belgium & 0.64 & 0.105 & 0.49 & 0.181 & 0.64 & 0.200 \\
Denmark & 0.64 & 0.037 & 1.46 & 0.374 & 1.77 & 0.371 \\
Finland & 0.60 & 0.043 & 0.65 & 0.525 & 0.64 & 0.532 \\
Ireland & 0.46 & 0.053 & 0.40 & 0.330 & 0.66 & 0.429 \\
Netherlands & 0.69 & 0.082 & 2.04 & 0.689 & 1.94 & 0.583 \\
Norway & 0.66 & 0.072 & 0.77 & 0.338 & 0.88 & 0.429 \\
Spain & 0.55 & 0.050 & 0.70 & 0.212 & 0.91 & 0.257 \\
Sweden & 0.60 & 0.063 & 1.87 & 0.298 & 0.97 & 0.395 \\
Switzerland & 0.67 & 0.196 & 0.64 & 0.272 & 0.80 & 0.230 \\
\hline Mean & 0.61 & 0.076 & 1.15 & 0.380 & 1.16 & 0.353 \\
Standard deviation & 0.080 & 0.037 & 0.626 & 0.238 & 0.661 & 0.150 \\
\hline
\end{tabular}

* For details, see Annex Tables A1-A3.

These findings have two interdependent implications for the expected changes in the ex post relative returns and factor incomes. First, because of the time required to adjust the capital stock in accordance with changes in relative factor prices, firms will be operating with sub-optimal factor ratios and, more specifically, with too little capital. Consequently, ex post measures of the return to capital are likely to contain an element of excess profits. ${ }^{24}$ Second, due to the time lags, the elasticities of substitution that are relevant in evaluating the production adjustment functions and its implications for factor returns and incomes are well below unity. As a result, using the technical substitution elasticities to predict changes in ex post relative returns will give a highly misleading impression, as can be seen from columns 4 and 5 of Table 5. Changes in the distribution of factor income are more difficult to predict, because the actual change will depend on the size of the substitution elasticity as well as the actual change in the capital/labour ratio. In addition, ex post changes in relative factor shares may be influenced by other changes in firm behaviour.

23 Alternative measures of real long-term interest rates are discussed in Andersen (1999).

24 The relatively low elasticities of substitution generated by the factor adjustment functions would imply that firms have not increased their capital stocks corresponding to the technical substitution elasticities $\left(\sigma_{1}\right)$ in Table 4 and the rise in relative labour costs. This reluctance to increase investment (or the lags in the adjustment process) has, obviously, attenuated the downward pressures on the ex post return to capital. 
In fact, as can be seen from Annex Tables A2 and A3, the slow change in factor ratios is not the only reason for discrepancies between actual and expected changes in relative factor returns and factor shares. For about two-thirds of the countries, the coefficient on the rate of unemployment is highly significant and for some of the European countries the rise in unemployment seems to account for a substantial part of the increase in the profit share and the relative return to capital. ${ }^{25}$ The hypothesis that higher real interest rates tend to boost profit margins is also quite well accepted by the data. However, despite large interest rate effects for intermediate years, such effects tend to be only transitory and, for the period as a whole, real interest rates have had only a moderate impact. ${ }^{26}$ For most countries, the effect of real output growth is positive and highly significant, with the size of the coefficient suggesting that it may be capturing demand-side effects as well as the pro-cyclical behaviour of profits.

The estimated equations are also quite successful at predicting changes in factor income ratios and relative returns (Table 5, columns 3 and 6) and the implied "pseudo" elasticities of substitution in Table 6 are, except for a few cases, not implausible. ${ }^{27}$ On average, they tend to be below the technical substitution elasticities $\left(\sigma_{1}\right)$ in Table 4 , but not too different from those $\left(\sigma_{2}\right)$ derived directly from equation (vi). This implicitly suggests that ex post factor shares and relative returns respond more quickly than factor ratios. This is also seen from the implied speeds of adjustment which, for most countries, indicate that one-third to one half of the "gap" between the actual and the long-run ratios of factor incomes and factor returns is closed within one year. In contrast, for factor proportions, less than $10 \%$ of the gap between actual and desired ratios is closed within one year.

\section{Summary and conclusions}

The second section of this paper looked at the sources of changes in profit shares and rates of return since the mid-1960s. Most earlier analyses have attributed the decline in profit shares until the early 1980s and the subsequent recovery to changes in real wages relative to labour productivity growth. However, using a new decomposition, we find that real profits per person employed actually increased during the period 1966-81 and that most of the decline in profit shares can be attributed to an exceptionally large increase in the capital/labour ratio which was not sufficiently matched by higher labour productivity. Over the next fifteen years, the moderation of real wage growth helped to raise

25 We are well aware of the fact that, even when entered with lags, the rate of unemployment is likely to be endogenous, so that the coefficients may be biased. However, we have postponed further analysis of this issue until the demand side of the model has been developed in more detail.

26 This is consistent with what theory would predict, as monetary policy is neutral with respect to long-run real output.

27 We refer to these as "pseudo" elasticities since they are obtained from equations with relative factor returns or factor shares as the dependent variable. Moreover, firms do not choose their factor ratios on the basis of ex post figures. 
real profits per person employed, while the rate of growth of the capital/labour ratio slowed. An additional factor was a marked fall in the price of capital relative to both output prices and wages.

While the discussion in Section 2 is merely based on a decomposition of profit share changes, Section 3 looks into the underlying adjustment process, in particular changes in capital/labour ratios and the puzzling slowdown in capital spending during a period when investment conditions were favourable. The evidence and the implications can be summarised in three major points.

First, from the elasticities of substitution presented in Table 4 it would appear that firms do not take full advantage of the technical substitution possibilities, as the elasticities based on the cost minimisation assumption $\left(\sigma_{2}\right)$ are well below the technical elasticities $\left(\sigma_{1}\right){ }^{28}$ However, when estimating the equations on variables in first differences rather than in levels, the elasticities drop substantially, implying that an equation in levels is misspecified due to long adjustment lags.

Second, while such lags would slow the adjustment of ex post factor returns towards their long-run equilibrium levels, the evidence presented in Table 5 implies that other factors have also influenced this process, as actual returns differ substantially from those predicted by changes in capital/labour ratios since 1981. In particular, the real return to capital has fallen only marginally (or even increased) relative to that to labour, possibly indicating that firms have enjoyed significant excess returns.

Third, when adopting an error correction framework for estimating the underlying production function and the path of relative factor returns, several interesting results are obtained.

(i) The adjustment of capital/labour ratios to changes in relative factor prices is indeed very slow as for most countries less than $10 \%$ of the 'gap' between actual and desired (i.e. cost minimising) factor ratios is closed within one year. It thus appears that the underlying production function is putty-clay rather than putty-putty, so that, given the fall in relative capital prices, firms have been operating with sub-optimal capital/labour ratios for most of the last fifteen years.

(ii) Ceteris paribus, the slow adjustment of factor proportions could also have impeded the demand for labour. If firms had been operating with optimal capital/labour ratios, the marginal productivity of labour would have been higher, potentially increasing employment through an upward shift in the demand curve for labour. ${ }^{29}$

(iii) While the long adjustment lags go a long way towards explaining the rise in profit shares and in the relative return to capital, they do not go far enough as other factors have also raised the return to capital relative to that to labour. In Spain, for instance, the dampening effect on real wages of the rise in unemployment since the early 1980s has more than offset the fall in the return to capital as a result

28 This would also suggest that the assumption that the ratio of marginal productivities equals relative factor prices is not satisfied.

29 On the other hand, actual employment has been higher than it would have been if actual output had been produced under
optimal conditions. 
of the rise in the capital/labour ratio over the same period. In Germany, the two effects are about equally large, while, in Italy, the rise in unemployment has offset about two-thirds of the fall in the relative return to capital due to the higher capital/labour ratio. The rise in real interest rates during the early 1980s has also strengthened the relative return to capital. However, unlike the influence of unemployment, this effect has, for most countries, been only transitory.

The sub-optimal capital/labour ratios, combined with the high profit shares, also make it easier to understand policy-makers' concern that individual firms seem to prefer investing their profits in financial assets rather than expanding their own real assets. Similarly, the empirical results justify unions' claims that real wage moderation has mostly served to boost profits and has not been accompanied by job-creating investment.

Nonetheless, given the preliminary nature of the estimates, some caution is called for in attributing sluggish investment to adjustment lags (or putty-clay capital structures) alone. It still cannot be excluded that firms have underestimated expected returns on additions to their capital stocks and, as a result, have invested too little. On the other hand, our interpretation of $\mu$ as a measure of revealed user costs or as an indicator of excess returns may be false. First, the apparent rise in $\mu$ could indicate that firms' opportunity costs have risen as they are increasingly relying on financial markets rather than banks as a source of external financing. In fact, this could explain firms' reluctance to embark on irreversible expansions of their own capital stocks and their preference for indirect investment in financial assets. Second, because the measured rise in the rate of return to capital is partly the result of falling real prices of capital goods, it could be argued that rates of return as well as profit shares are overstated as they are not corrected for capital losses on the existing stock. Fears that demand would not be sufficiently strong may also have dampened investment intentions and spending; and there might be further reasons, which we have not considered.

All in all, a study focused on the supply-side response can provide only a partial evaluation of the apparent weak response of capital formation to the boom in profits and the fall in relative capital costs. Demand-side effects and financial market developments are other and equally important parts which we plan to pursue in a separate and later study. Such a study is relevant not only in its own right but also, and not least, to provide a more comprehensive basis for identifying policy implications. 


\section{Annex}

\section{Investment/output ratios and optimal capital stocks}

Developments in investment/output ratios

As discussed in the main text, most countries have experienced a slowdown in the rate of growth of capital compared with both output and labour. Allied with a trend decline in investment relative to output, this has led to concerns that, in some sense, investment is too low. European policy-makers have mainly worried about the risk that capital shortages might constrain future growth of output and employment, while US policy-makers have seen weak capital formation as a major reason for the slow rate of labour productivity growth. ${ }^{30}$

Measured in current prices, the fall in investment relative to output since 1981 has, indeed, been substantial and widespread (Table 1, columns 1 and 2). On average for the seventeen countries, the investment/output ratio has declined by over 31/2 percentage points, with only Denmark and Spain managing to raise the ratio or prevent it from falling. The decline in the proportion of profits spent on investment appears to be even more dramatic (columns 3 and 4$)^{31}$ and, in countries where wage moderation has been seen as a precondition for more investment and employment growth, this may pose a threat to continued wage moderation. Although the $33 \%$ drop should be seen against the unusually low profit shares in the early 1980s, it is suggestive of a growing reluctance to invest in real assets. This is especially the case when the progressive easing of credit conditions and the rise in equity prices are also taken into account. ${ }^{32}$

However, some qualifications to these gloomy assessments are called for. First, because of the fall in the real price of capital goods, measures in current prices give a misleading impression of the extent to which firms' investment intentions have weakened. Measured in constant prices (columns 5 and 6), investment/output ratios have fallen by only 1 percentage point on average since 1981 . The change is most pronounced for the United States and Canada, where the contraction in real capital goods prices has been most dramatic. ${ }^{33}$ In contrast, even in constant prices, large and structurally induced declines are still observed in Norway, Finland, Ireland and Belgium. In most other European countries and

30 Such arguments are sometimes based on the simple Cobb-Douglas function we used in note 8. From this it is easily seen that higher growth of the capital/labour ratio will increase the growth of labour productivity.

31 The investment/profit ratios should not be interpreted as the inverse of self-financing ratios, as capital income is not corrected for taxes and dividends and, in the case of non-financial firms, net interest payments.

32 For further discussion, see Browne and Hellerstein, op cit.

33 The relatively large declines observed for the United States and Canada are, in part, related to the fact that these are among the few countries, which apply hedonic price indices for computers. 
Australia, the move from current to constant prices mainly helps to moderate the fall in investment/output ratios.

Second, (Table 1, columns 7 and 8), investment per employed worker has increased over the last fifteen years. Even though the United States obtains a low rank with respect to the level of the investment/output ratio, capital formation was sufficiently strong to support an increase in investment per employed worker as well as a substantial expansion in the number of persons employed. ${ }^{34}$ The investment/employment ratios also rose in Canada and the United Kingdom, despite relatively fast employment growth. In continental Europe, by contrast, the increase in investment/employment ratios mostly reflects the slow growth (or actual decline) of employment and the capital-deepening nature of the investment undertaken. ${ }^{35}$

\section{Saturation and optimal capital/output ratios}

Despite the above qualifications, it could still be argued, that with profits growing and the relative price of capital goods declining, firms could have undertaken more real investment and prevented the slowdown in the growth of capital/output ratios rather than boosting their purchases of financial assets. In this context, some have argued that one reason for the hesitant capital spending might be that, by the early or mid-1980s, capital stocks had become "too large" so that firms preferred to reduce the growth of their real assets to improve their rates of return. As noted in the text, Irish enterprises seem to have produced an exceptionally large rise in their rates of return by reducing their capital/output ratio. Similarly, though on a smaller scale, firms in Denmark, Finland, the Netherlands and Spain have seen a marked rise in rates of return, while capital/output ratios have fallen or grown at a slower rate than during the previous fifteen years.

While firms' reaction to the low rates of return in the 1980s may be entirely rational from the point of view of maximising profits, the resulting slowdown in investment spending, nevertheless, raises the question whether the trend decline in investment/output ratios has reached a point where it poses a risk to output growth. In other words, is investment spending so low that earlier estimates of potential rates of output growth need to be revised down?

We attempt to answer these questions using various measures derived from the "golden rule" of accumulation as proposed by Phelps (1961). According to this rule, the capital stock should be expanded until the marginal product of capital equals the natural rate of growth of the economy, or:

\footnotetext{
34 The US investment/employment ratio is probably understated, as the United States has not only seen a marked decline in relative capital goods prices but capital goods also tend to be cheaper in the United States than in other countries. For further discussion, see Kirova and Lipsey, op cit.

35 For instance, if, over the period 1991-96, Germany and France were to have increased employment by, respectively, 2 and 1.5 million more than they actually did and thus reduced the rate of unemployment in 1996 to 5-6\%, the investment/output ratios should, ceteris paribus, have been 19-20\% rather than 14-15\%. Except for 1991-92, when German investment was boosted by reunification expenditure, neither country has recorded such investment ratios for the last thirty years.
} 


$$
r-\delta=g=n+\tau
$$

where $r=$ the marginal product of capital, $\delta=$ the rate of scrapping, $g=$ the natural or potential rate of growth, $n=$ the rate of growth of the labour force and $\tau=$ the rate of growth of labour augmenting technical progress. Assuming a Cobb-Douglas technology and competitive markets, (i) can be rewritten as:

(ii) $K / Y=\alpha / r$

where $\alpha=$ capital's share of income. The corresponding rule for steady-state investment (net of scrapping, $I^{n}$ ) can be derived from:

$$
I^{n}=\Delta K=g K
$$

which, after dividing by output on both sides, gives:

$$
I^{n} / Y=g(K / Y)=g(\alpha / r)
$$

In Table 2, we have used the above relations, taking 1981 as a starting point and ranking the countries according to the actual change in capital/output ratios over the period 1981-96. In Table 3 we then evaluate current investment and capital ratios against the golden rule requirements. Because most of the parameters and variables in (ii) and (iv) are subject to uncertainty, both tables provide ranges rather than point estimates. Starting with Table 2, columns 1 and 2 present plausible ranges for capital/output ratios, using equation (ii) as explained in the notes, while the actual ratios are shown in column 3. The next four columns of the table then compare actual investment ratios to those implied by the golden rule and the maximum and minimum capital/output ratios as shown in the first two columns. ${ }^{36}$

As the table shows, in 1981, actual capital/output ratios in Ireland, the United Kingdom, the Netherlands and Finland were rather close to the levels implied by the golden rule. This may, in part, explain the subsequent reduction in investment spending and in the capital intensiveness of output in these countries. Similarly, the slow growth of the capital/output ratio in Australia looks more plausible, once the initial situation is taken into account. Conversely, the relatively high growth of the capital/output ratios of Canada and Switzerland may be justified by the fact that, in 1981, actual ratios were far below the ranges implied by the golden rule.

Nonetheless, even with the low profit shares of the early 1980s, actual capital/output ratios were generally rather low compared with golden rule ratios. Consequently, if firms were to have reduced the gap between actual and optimal capital/output ratios, investment/output ratios should, at least

36 We have also included the investment ratios required to maintain average growth for the 1990s without reducing the capital stock. However, in most cases, actual growth rates have been well below potential rates of growth, so that the "required" ratios are mostly very low and of relatively little interest. It might also be noted that the maximum and minimum investment ratios contain an inconsistency with respect to the potential growth rates used. However, the inconsistency is deliberate as it helps to widen the evaluation range. 
temporarily, have been increased rather than reduced. From this perspective, investment appears to have been relatively low in continental Europe. In contrast, even though the US ratio is low compared with most other countries, it is close to the maximum of the range and thus sufficiently high to raise the actual capital/output ratio and maintain growth.

However, these evaluations are based on the very low profit shares of the early 1980s and a more relevant question is, perhaps, whether firms' willingness to invest has remained sufficiently strong, once the improvement in profits and the change in capital goods prices over the last fifteen years are taken into account. This is further analysed in Table 3 where, in the first four columns, we augment the earlier table by adding average values for the last five years for output growth, scrapping rates and gross and net profit shares. With the exception of the United Kingdom, actual capital/output ratios are well below the ranges implied by the golden rule, suggesting that fears of saturation are unlikely to have constrained investment spending. Moreover, as shown in the last four columns of the table, actual investment/output ratios are, for several countries, higher than or just below the maximum golden rule requirements and thus suggestive of attempts to bring future capital/output ratios closer to their optimal level. This is the case for the United States, Japan, the United Kingdom, Canada and Norway. In contrast, for the continental EU countries as well as Australia and Ireland, actual investment ratios again seem rather low, thus confirming policy-makers' concerns that weak investment may constrain future employment.

However, two caveats are called for in evaluating the above results. First, the recent rise in profit shares has significantly raised the golden rule ratios compared with the early 1980s. If, however, firms were to regard this improvement as cyclical and/or temporary, their intentions with respect to investment and the growth of their capital/output ratios would be below the figures shown in Table 3 . Second, it needs to be kept in mind that the golden rule applies only to an economy in steady state and that, for most countries, the last fifteen years mark a period of transition between steady states. 
Table 1

Indicators of investment and capital stocks

\begin{tabular}{|c|c|c|c|c|c|c|c|c|c|c|c|}
\hline \multirow[t]{2}{*}{ Countries } & \multicolumn{2}{|c|}{$I * P_{K} / Y^{*} P_{Y}$} & \multicolumn{2}{|c|}{$I^{*} P_{K} / P r$} & \multicolumn{2}{|c|}{$I / Y$} & \multicolumn{2}{|c|}{ I/Em } & \multicolumn{2}{|c|}{$K / Y$} & \multirow{2}{*}{$\begin{array}{c}\text { PPP } \\
1990\end{array}$} \\
\hline & 1996 & 1981 & 1996 & 1981 & 1996 & 1981 & 1996 & 1981 & 1996 & 1981 & \\
\hline Norway & 34.9 & 44.0 & 105.1 & 162.8 & 33.8 & 43.8 & 18.8 & 18.9 & 4.1 & 3.9 & 0.65 \\
\hline Japan & 20.1 & 21.9 & 60.4 & 72.3 & 21.9 & 19.4 & 10.1 & 6.6 & 2.6 & 2.0 & 0.74 \\
\hline Canada & 18.0 & 24.9 & 53.2 & 65.4 & 18.2 & 17.6 & 7.1 & 5.7 & 2.1 & 1.3 & 0.90 \\
\hline Australia & 17.0 & 21.7 & 45.5 & 66.6 & 18.5 & 20.6 & 6.9 & 6.2 & 2.3 & 2.3 & 0.92 \\
\hline Denmark & 16.9 & 13.4 & 44.5 & 51.1 & 17.3 & 13.2 & 8.5 & 4.6 & 3.6 & 3.5 & 0.66 \\
\hline Spain & 16.3 & 16.3 & 37.5 & 56.9 & 17.5 & 14.7 & 6.1 & 3.6 & 2.3 & 1.9 & 0.93 \\
\hline Sweden & 14.9 & 16.0 & 48.1 & 61.6 & 16.9 & 13.8 & 10.7 & 6.2 & 2.9 & 2.6 & 0.63 \\
\hline United Kingdom & 14.9 & 16.1 & 45.0 & 53.3 & 16.4 & 15.5 & 6.0 & 4.4 & 3.3 & 3.6 & 0.93 \\
\hline Germany & 14.4 & 15.4 & 38.1 & 49.7 & 15.5 & 15.0 & 8.1 & 6.3 & 2.9 & 2.7 & 0.77 \\
\hline Netherlands & 14.0 & 15.3 & 35.4 & 45.1 & 14.3 & 15.4 & 4.6 & 2.7 & 2.2 & 2.4 & 0.84 \\
\hline Finland & 13.9 & 20.0 & 41.4 & 70.5 & 14.6 & 20.5 & 9.7 & 7.8 & 3.4 & 3.6 & 0.60 \\
\hline Switzerland & 13.9 & 18.6 & 44.6 & 53.0 & 18.8 & 18.6 & 8.5 & 6.9 & 2.7 & 2.2 & 0.63 \\
\hline France & 13.6 & 16.2 & 33.2 & 50.4 & 14.5 & 15.4 & 4.7 & 3.6 & 2.7 & 2.6 & 0.82 \\
\hline Italy & 13.3 & 16.3 & 31.4 & 47.2 & 13.7 & 14.2 & 6.7 & 5.1 & 2.8 & 2.6 & 0.84 \\
\hline Ireland & 13.2 & 26.8 & 30.4 & 109.7 & 12.7 & 22.6 & 5.5 & 5.4 & 2.1 & 3.0 & 0.87 \\
\hline Belgium & 12.8 & 19.6 & 34.7 & 67.0 & 13.1 & 17.5 & 8.4 & 5.0 & 2.7 & 2.4 & 0.84 \\
\hline United States & 12.7 & 16.3 & 37.1 & 49.8 & 13.9 & 13.1 & 6.8 & 5.6 & 2.0 & 1.9 & 1.00 \\
\hline Average* & 16.2 & 19.9 & 45.0 & 66.6 & 17.3 & 18.3 & 8.2 & 6.2 & 2.75 & 2.60 & - \\
\hline
\end{tabular}

Notation: $I^{*} P_{K} / Y^{*} P_{Y}$ : investment/output ratio, current prices; $I / Y$ : investment/output ratio, constant prices; $I / E m$ : investment/labour ratio in US dollars at 1990 exchange rates; $I * P_{K} / P r$ : investment/profit ratio, current prices; K/Y: capital/output ratio at 1990 prices and PPP rates; and PPP: 1990 PPP rates.

*Unweighted. 
Table 2

Investment and capital output ratios: actual relative to "golden rules", 1981

In ratios and percentages

\begin{tabular}{|c|c|c|c|c|c|c|c|c|}
\hline \multirow[t]{2}{*}{ Countries } & \multicolumn{3}{|c|}{ Capital/output ratios ${ }^{1}$} & \multicolumn{3}{|c|}{ Investment/output ratios $^{2}$} & \multicolumn{2}{|c|}{$\Delta(K / Y)$} \\
\hline & Maximum & Minimum & Actual & Maximum & Minimum & "Required" & Actual & 1981-96 \\
\hline Ireland & 4.1 & 2.8 & 3.00 & 14.3 & 7.0 & 15.3 & 22.1 & -2.2 \\
\hline United Kingdom & 4.4 & 3.3 & 3.60 & 15.4 & 8.2 & 4.3 & 15.0 & -0.6 \\
\hline Netherlands & 5.2 & 3.8 & 2.40 & 18.2 & 9.5 & 3.5 & 14.7 & -0.6 \\
\hline Finland & 5.2 & 3.7 & 3.55 & 18.2 & 9.2 & 11.2 & 20.0 & -0.3 \\
\hline Norway & 6.4 & 4.3 & 3.95 & 22.5 & 10.7 & 9.4 & 43.0 & 0.2 \\
\hline Australia & 6.3 & 4.4 & 2.30 & 22.0 & 11.0 & 7.3 & 20.0 & 0.2 \\
\hline Denmark & 6.6 & 4.3 & 3.50 & 23.0 & 10.7 & 3.6 & 14.2 & 0.2 \\
\hline United States & 3.6 & 2.8 & 1.90 & 12.6 & 7.0 & 6.1 & 12.3 & 0.2 \\
\hline Germany & 5.4 & 3.9 & 2.75 & 18.9 & 9.7 & 6.0 & 14.5 & 0.3 \\
\hline France & 5.8 & 4.1 & 2.55 & 20.3 & 10.3 & 7.0 & 15.0 & 0.4 \\
\hline Italy & 7.7 & 5.2 & 2.60 & 27.0 & 13.0 & 8.8 & 13.8 & 0.6 \\
\hline Sweden & 4.9 & 3.5 & 2.60 & 17.1 & 8.7 & 0.5 & 13.5 & 0.7 \\
\hline Belgium & 6.2 & 4.2 & 2.75 & 21.6 & 10.5 & 3.4 & 17.0 & 0.9 \\
\hline Spain & 4.6 & 3.3 & 1.95 & 16.1 & 8.2 & 1.6 & 14.2 & 1.2 \\
\hline Switzerland & 7.8 & 5.2 & 2.20 & 27.3 & 13.0 & 4.8 & 18.6 & 1.4 \\
\hline Japan & 4.5 & 3.3 & 2.00 & 15.7 & 8.0 & 8.5 & 18.5 & 1.8 \\
\hline Canada & 5.6 & 4.1 & 1.30 & 19.5 & 10.2 & 4.8 & 17.0 & 3.3 \\
\hline
\end{tabular}

${ }^{1}$ Maximum and minimum capital output ratios calculated from the formula: $K / Y^{*}=\alpha /(\Delta y *+\delta)$, with $\alpha=$ gross (net) profit share for the maximum (minimum), $\Delta y^{*}=$ potential output growth, with $2.5 \%$ (3.5\%) assumed for the maximum (minimum), and $\delta=$ scrapping rate, with actual scrapping rate less (plus) 0.5 percentage points used for the maximum (minimum). ${ }^{2}$ Maximum and minimum net investment ratios are calculated from the formula: $I^{n} / Y=\Delta y^{*} K / Y^{*}$, with $K / Y^{*}$ corresponding to the maximum and minimum capital ratios and $\Delta y^{*}$ assumed to equal $3.5 \%$ and $2.5 \%$ respectively; "required" ratio calculated as actual capital/output ratio times actual growth rate. 
Table 3

Investment and capital output ratios: actual relative to "golden rules"

In ratios and percentages

\begin{tabular}{|c|c|c|c|c|c|c|c|c|c|c|c|}
\hline \multirow[t]{2}{*}{ Countries } & \multicolumn{4}{|c|}{ Average values, $1992-96^{1}$} & \multicolumn{3}{|c|}{ Capital/output ratios $^{2}$} & \multicolumn{4}{|c|}{ Investment/output ratios $^{3}$} \\
\hline & $\Delta y$ & $\delta$ & $\left(\pi / Y * P_{y}\right)^{g}$ & $\left(\pi / Y * P_{y}\right)^{n}$ & Maximum & Minimum & Actual & Maximum & Minimum & "Required" & Actual \\
\hline Ireland & 6.8 & 2.75 & 31.5 & 30.5 & 6.6 & 4.5 & 2.15 & 23.1 & 11.2 & 14.6 & 12.5 \\
\hline United Kingdom & 3.0 & 4.5 & 31.0 & 29.0 & 4.8 & 3.4 & 3.30 & 16.8 & 8.5 & 9.9 & 15.7 \\
\hline Netherlands & 2.6 & 4.5 & 38.6 & 36.9 & 5.9 & 4.3 & 2.20 & 20.6 & 10.7 & 5.7 & 14.8 \\
\hline Finland & 2.0 & 3.5 & 30.5 & 29.5 & 5.5 & 3.9 & 3.45 & 19.2 & 9.7 & 6.9 & 14.0 \\
\hline Norway & 3.6 & 2.25 & 33.5 & 32.7 & 7.9 & 5.2 & 4.05 & 27.6 & 13.0 & 14.6 & 33.0 \\
\hline Australia & 4.4 & 3.25 & 38.5 & 37.2 & 7.3 & 5.1 & 2.35 & 25.5 & 12.7 & 10.3 & 17.9 \\
\hline Denmark & 2.4 & 2.0 & 37.5 & 36.7 & 9.4 & 6.1 & 3.60 & 32.9 & 15.2 & 8.6 & 16.6 \\
\hline United States & 2.9 & 7.0 & 34.0 & 31.5 & 3.8 & 2.9 & 1.95 & 13.3 & 7.2 & 5.8 & 12.9 \\
\hline Germany & 1.4 & 3.75 & 35.8 & 34.5 & 6.2 & 4.5 & 2.85 & 21.7 & 11.2 & 4.0 & 15.0 \\
\hline France & 1.2 & 3.5 & 40.5 & 39.2 & 7.4 & 4.9 & 2.75 & 25.9 & 12.3 & 3.3 & 14.0 \\
\hline Italy & 1.2 & 2.5 & 39.8 & 38.0 & 8.8 & 5.8 & 2.85 & 30.8 & 14.5 & 3.5 & 13.5 \\
\hline Sweden & 1.6 & 3.25 & 34.0 & 33.0 & 6.5 & 5.3 & 2.90 & 22.7 & 13.2 & 4.6 & 16.3 \\
\hline Belgium & 1.4 & 2.75 & 35.7 & 34.7 & 7.5 & 5.1 & 2.75 & 26.2 & 12.7 & 3.8 & 14.3 \\
\hline Spain & 1.4 & 3.75 & 38.5 & 37.2 & 6.7 & 4.8 & 2.35 & 23.5 & 12.0 & 3.3 & 17.0 \\
\hline Switzerland & 0.0 & 2.5 & 30.7 & 29.9 & 6.8 & 4.6 & 2.70 & 23.8 & 11.5 & 4.0 & 18.8 \\
\hline Japan & 1.4 & 4.75 & 33.0 & 31.5 & 4.9 & 3.6 & 2.60 & 17.1 & 9.0 & 3.6 & 20.9 \\
\hline Canada & 2.4 & 4.0 & 29.5 & 28.0 & 4.9 & 3.5 & 2.15 & 11.8 & 8.7 & 5.2 & 17.5 \\
\hline
\end{tabular}

Notes and notation: ${ }^{1} \Delta y$ : average growth of real GDP; $\delta$ : scrapping rate; $\left(\pi / Y * P_{y}\right)^{g}$ : gross profit share; and $\left(\pi / Y * P_{y}\right)^{n:}$ net profit share. ${ }^{2}$ Maximum and minimum capital output ratios calculated from the formula: $K / Y^{*}=\alpha /\left(\Delta y^{*}+\delta\right)$, with $\alpha=$ gross (net) profit share for the maximum (minimum), $\Delta y^{*}=$ potential output growth, with $2.5 \%$ (3.5\%) assumed for the maximum (minimum), and $\delta=$ scrapping rate, with actual scrapping rate less (plus) 0.5 percentage points used for the maximum (minimum). ${ }^{3}$ Maximum and minimum net investment ratios are calculated from the formula: $I^{n} / Y=\Delta y * K / Y^{*}$, with $K / Y^{*}$ corresponding to the maximum and minimum capital ratios and $\Delta y^{*}$ assumed to equal $3.5 \%$ and $2.5 \%$ respectively; "required" ratio calculated as actual capital/output ratio times actual growth rate (for Switzerland, however, actual growth rate replaced by $1.5 \%$ ). 
Annex Tables

Table A1

Production adjustment functions ${ }^{1}$

\begin{tabular}{|c|c|c|c|c|c|c|c|c|}
\hline Countries & klem $_{-1}$ & $w / p_{k-1}$ & $\Delta y$ & $\Delta\left(w-p_{k}\right)_{-i}$ & $\begin{array}{c}\Delta(k-e m)_{-} \\
1\end{array}$ & $R^{2}$ & $D W^{2}$ & $\sigma_{5}^{3}$ \\
\hline United States & -0.077 & 0.043 & $-0.64 * *$ & - & 0.16 & 0.67 & 1.52 & 0.56 \\
\hline Japan $^{4}$ & $-0.034 * *$ & $0.022 * *$ & $0.22 * *$ & - & $0.49 * *$ & 0.83 & 2.50 & 0.65 \\
\hline Germany & $-0.053 * *$ & $0.042 * *$ & $-0.32 * *$ & - & $0.32 * *$ & 0.47 & 1.36 & 0.78 \\
\hline France & $-0.075^{* *}$ & $0.039 * *$ & $-0.40 * *$ & - & - & 0.65 & 1.53 & 0.52 \\
\hline Italy & $-0.089 * *$ & $0.058 * *$ & $-0.43 * *$ & $0.12 *$ & - & 0.47 & 1.15 & 0.65 \\
\hline United Kingdom & $-0.079 * *$ & $0.038 * *$ & $-0.59 * *$ & $0.16^{* *}$ & - & 0.75 & 2.05 & 0.48 \\
\hline Canada & $-0.081 * *$ & $0.051 * *$ & $-0.82 * *$ & $0.16 * *$ & - & 0.75 & 2.01 & 0.64 \\
\hline Australia & $-0.102 * *$ & $0.064 * *$ & $-0.55 * *$ & - & - & 0.55 & 2.58 & 0.63 \\
\hline Belgium & $-0.105^{* *}$ & $0.068 * *$ & $-0.28 * *$ & - & - & 0.62 & 1.49 & 0.64 \\
\hline Denmark & $-0.037 * *$ & $0.024 * *$ & $-0.39 * *$ & $0.15^{*}$ & $0.33 * *$ & 0.77 & 4.67 & 0.64 \\
\hline Finland & $-0.043^{* *}$ & $0.026 * *$ & $-0.51 * *$ & - & $0.25 * *$ & 0.70 & 5.11 & 0.60 \\
\hline Ireland & $-0.053 * *$ & $0.025 * *$ & $-0.30 * *$ & $0.10^{*}$ & $0.44 * *$ & 0.65 & 5.52 & 0.46 \\
\hline Netherlands & $-0.082 * *$ & $0.056^{* *}$ & $-0.33 * *$ & $0.15^{*}$ & $0.38 * *$ & 0.76 & 4.45 & 0.69 \\
\hline Norway & $-0.072 * *$ & $0.047 * *$ & $-0.77 * *$ & - & - & 0.60 & 2.29 & 0.66 \\
\hline Spain & $-0.050 * *$ & $0.028 * *$ & $-0.35^{* *}$ & $0.16^{*}$ & $0.37 * *$ & 0.81 & 32.9 & 0.55 \\
\hline Sweden & $-0.063 * *$ & $0.038 * *$ & $-0.56 * *$ & $0.13 * *$ & - & 0.71 & 1.60 & 0.60 \\
\hline Switzerland & $-0.196 * *$ & $0.131 * *$ & $-0.44 * *$ & -0.16 & $0.40 * *$ & 0.63 & 5.65 & 0.67 \\
\hline
\end{tabular}

${ }^{1}$ Coefficients obtained from estimating the following error correction model (all variables in logs):

$\Delta(k-e m)=\beta(k-e m)_{-1}+\varphi\left(w-p_{k}\right)_{-1}+\lambda \Delta y+\phi \Delta\left(w-p_{k}\right)_{-i}+\rho \Delta(k-e m)_{-i}+\varepsilon$

with $k$-em $=$ capital/labour ratio, $w-p k$, = relative factor prices, $\Delta y=$ rate of output growth, $\varepsilon=$ random error and $\Delta=$ firstdifference operator. ${ }^{2}$ Durbin's $h$ when lagged dependent variable included. ${ }^{3}$ Calculated as $\varphi / \beta$. $*$ and $* *$ denote significance levels of respectively $5 \%$ and $1 \%$ respectively. ${ }^{4} \Delta y$ entered with one lag. 
Table A2

Developments in factor ratios and relative factor shares ${ }^{1}$ Rate of return to capital/real labour costs

\begin{tabular}{|c|c|c|c|c|c|c|c|c|}
\hline Countries & k/em*-1 & $\pi / w \cdot e m_{-1}$ & $\Delta y_{-i}$ & $U_{-i}^{2}$ & Rint $_{-i}{ }^{3}$ & $\Delta k / e{ }^{*}{ }_{-1}$ & $R^{2} / D W$ & $\sigma_{6}^{4}$ \\
\hline United States & $0.289 * *$ & $-0.617 * *$ & $0.63^{* *}$ & - & - & - & $0.51 / 1.93$ & 1.88 \\
\hline Japan & $0.049 *$ & $-0.167 * *$ & $1.42 * *$ & - & $0.56^{* *}$ & - & $0.76 / 2.14$ & 1.41 \\
\hline Germany $^{5}$ & $-0.193 * *$ & $-0.171 * *$ & - & $0.26^{* *}$ & - & - & $0.57 / 1.95$ & 0.53 \\
\hline France & $0.066 * *$ & $-0.250 * *$ & $1.44^{* *}$ & - & $1.53 * *$ & - & $0.72 / 2.02$ & 1.36 \\
\hline Italy $^{6}$ & $0.141 * *$ & $-0.251 * *$ & $0.20^{* *}$ & - & $1.20 * *$ & - & $0.52 / 1.81$ & 2.28 \\
\hline United Kingdom ${ }^{6,7}$ & $-0.345^{* *}$ & $-0.897 * *$ & $0.85^{* *}$ & $0.12^{* *}$ & - & $0.38 * *$ & $0.72 / 0.80$ & 1.54 \\
\hline Canada $^{6}$ & $-0.170 * *$ & $-0.381 * *$ & $0.79 * *$ & $0.17 * *$ & - & - & $0.48 / 1.99$ & 0.69 \\
\hline Australia $^{6,8}$ & $-0.113^{*}$ & $-0.254 * *$ & $1.55^{* *}$ & - & - & $1.36^{* *}$ & $0.54 / 2.20$ & 1.80 \\
\hline Belgium $^{9}$ & $-0.188 * *$ & $-0.181 * *$ & - & $0.98 *$ & $0.78 * *$ & -2.94 & $0.63 / 2.37$ & 0.49 \\
\hline Denmark ${ }^{10,6}$ & $0.117 *$ & $-0.374 * *$ & $1.52 * *$ & $0.87 *$ & - & - & $0.45 / 1.52$ & 1.46 \\
\hline Finland $^{6}$ & $-0.289 * *$ & $-0.525 * *$ & $0.90 * *$ & $0.20 * *$ & - & - & $0.68 / 1.88$ & 0.65 \\
\hline Ireland & -0.498 & $-0.330 *$ & $3.74 * *$ & $0.51 * *$ & 0.73 & - & $0.55 / 2.05$ & 0.40 \\
\hline Netherlands ${ }^{5}$ & $0.352 * *$ & $-0.689 * *$ & $1.24 * *$ & $0.19 * *$ & $2.76 * *$ & - & $0.73 / 1.73$ & 2.04 \\
\hline Norway $^{5}$ & $-0.099 * *$ & $-0.338 * *$ & - & $0.37 * *$ & - & - & $0.22 / 1.93$ & 0.77 \\
\hline Spain $^{5,7}$ & $-0.091 *$ & $-0.212 * *$ & $0.90 * *$ & $0.16^{* *}$ & - & $-0.32 * *$ & $0.53 / 0.07$ & 0.70 \\
\hline Sweden $^{5}$ & $0.139 * *$ & $-0.298 * *$ & $2.38 * *$ & $0.24 * *$ & - & - & $0.39 / 1.18$ & 1.87 \\
\hline Switzerland $^{6}$ & $-0.153 * *$ & $-0.272 * *$ & $0.88^{* *}$ & - & - & - & $0.33 / 1.62$ & 0.64 \\
\hline
\end{tabular}

${ }^{1}$ Coefficients obtained from estimating:

$\Delta \log (\pi / e m w)=\alpha+\beta \log (k / e m)_{-1}^{*}+\varphi \log (\pi / e m w)_{-1}+\lambda \Delta y_{-i}+\phi \log U_{-i}+\varphi r$ int $_{-i}+\rho \Delta \log (k / e m)_{-1}^{*}+\varepsilon$

with $\pi=$ profits, $e m w=$ wage sum, $k / e m^{*}=$ estimated capital/labour ratio, $\Delta y=$ rate of output growth, $U=$ rate of unemployment, rint $=$ real rate of interest, $i=0,1,2, \Delta=$ first-difference operator and $\varepsilon=$ random error term. $*$ and $* *$ denote significance levels of $5 \%$ and $1 \%$ respectively. ${ }^{2}$ Coefficients multiplied by 10 , except for log $U$. ${ }^{3}$ Coefficients multiplied by 100. ${ }^{4}$ Calculated as $-\varphi /\left(\beta \_\varphi\right) .{ }^{5} U$ rather than $\log U .{ }^{6} \Delta Q$ rather than $\Delta \log Q .{ }^{7}$ Lagged dependent variable rather than $\Delta \log$ $(\mathrm{k} / \mathrm{em}) .{ }^{8}$ Actual rather than fitted value for $\Delta(\mathrm{k}-\mathrm{em})_{-1}$; also includes an intercept dummy to capture the effects of exceptionally high wage increases in 1975 and $1982 .{ }^{9}$ Actual rather than fitted value for $\Delta(k-e m)_{-1}$. ${ }^{10}$ U only significant after 1981 . 
Table A3

Developments in factor ratios and relative factor returns ${ }^{1}$

Real return per unit of capital/real labour costs

\begin{tabular}{|c|c|c|c|c|c|c|c|c|}
\hline Countries & k/em* ${ }_{-1}$ & $r t / r w_{-1}$ & $\Delta y_{-I}$ & $U_{-i}^{2}$ & Rint $_{-i}{ }^{3}$ & $\Delta k / e{ }^{*}{ }_{-1}$ & $R^{2} / D W$ & $\sigma_{7}^{4}$ \\
\hline United States $^{5}$ & $-0.136 * *$ & $-0.434 * *$ & $1.76^{* *}$ & - & $0.71 *$ & $-1.16^{* *}$ & $0.85 / 1.61$ & 3.20 \\
\hline Japan & $-0.150 * *$ & $-0.240 * *$ & $1.43 * *$ & - & $0.63 * *$ & - & $0.85 / 1.96$ & 1.60 \\
\hline Germany $^{6}$ & $-0.443 * *$ & $-0.344 * *$ & $0.91 * *$ & $0.24 * *$ & - & - & $0.73 / 1.91$ & 0.77 \\
\hline France $^{6}$ & $-0.173 * *$ & $-0.181 * *$ & $1.87 * *$ & 0.10 & $1.04 * *$ & - & $0.79 / 2.12$ & 1.05 \\
\hline Italy $^{6}$ & $-0.404 * *$ & $-0.406 * *$ & $1.66^{* *}$ & $0.22 * *$ & - & - & $0.66 / 1.55$ & 1.00 \\
\hline United Kingdom ${ }^{7}$ & $-0.295^{* *}$ & $-0.395^{* *}$ & $2.83 * *$ & 1.15 & - & - & $0.60 / 1.90$ & 1.34 \\
\hline Canada $^{6}$ & $-0.482 * *$ & $-0.357^{*}$ & $1.40 * *$ & $0.25 * *$ & - & - & $0.57 / 1.78$ & 0.74 \\
\hline Australia $^{8}$ & $-0.246^{*}$ & $-0.400^{* *}$ & $2.34 * *$ & $0.54 * *$ & $0.11^{*}$ & $-2.70 * *$ & $0.90 / 1.62$ & 1.62 \\
\hline Belgium $^{9}$ & $-0.315^{* *}$ & $-0.201^{*}$ & - & - & $0.60 * *$ & $-3.73^{* *}$ & $0.82 / 2.33$ & 0.64 \\
\hline Denmark $^{10,6}$ & $-0.210^{* *}$ & $-0.371^{* *}$ & $2.04 * *$ & $0.88 *$ & - & - & $0.63 / 1.71$ & 1.77 \\
\hline Finland $^{6}$ & $-0.827 * *$ & $-0.532 * *$ & $1.11^{*}$ & $0.19 * *$ & 0.76 & - & $0.71 / 2.30$ & 0.64 \\
\hline Ireland & $-0.651 * *$ & $-0.429 * *$ & $3.95 * *$ & $0.40 * *$ & 1.16 & - & $0.57 / 1.90$ & 0.66 \\
\hline Netherlands & $-0.301 * *$ & $-0.583 * *$ & $2.40 * *$ & $0.15^{* *}$ & $2.13 * *$ & - & $0.84 / 1.95$ & 1.94 \\
\hline Norway $^{6}$ & $-0.487 * *$ & $-0.429 * *$ & - & $0.47 * *$ & - & - & $0.28 / 1.94$ & 0.88 \\
\hline Spain $^{6}$ & $-0.283^{* *}$ & $-0.257 * *$ & $1.44 * *$ & $0.15 * *$ & - & - & $0.69 / 2.72$ & 0.91 \\
\hline Sweden & $-0.408 * *$ & $-0.395 * *$ & $3.67 * *$ & $0.12 * *$ & - & - & $0.70 / 1.83$ & 0.97 \\
\hline Switzerland ${ }^{5}$ & $-0.287 * *$ & $-0.230 * *$ & $1.13 * *$ & - & - & $-0.77 * *$ & $0.64 / 1.95$ & 0.80 \\
\hline
\end{tabular}

${ }^{1}$ Coefficients obtained from estimating:

$\Delta \log (r r)=\alpha+\beta \log (k / e m)_{-1}^{*}+\varphi \log (r r)_{-1}+\lambda \Delta y_{-i}+\phi \log U_{-i}+\varphi r$ int $_{-i}+\rho \Delta \log (k / e m)_{-1}^{*}+\Delta \log \left(p_{k}-w\right)_{-i}+\varepsilon$

with $r r=$ real rate of return/real product wage, $k / e m^{*}=$ estimated capital/labour ratio, $\Delta y=$ rate of output growth, $U=$ rate of unemployment, rint $=$ real rate of interest, $i=0,1,2, \Delta=$ first-difference operator and $\varepsilon=$ random error term. $*$ and $* *$ denote significance levels of $5 \%$ and $1 \%$. respectively. ${ }^{2}$ Coefficient multiplied by 10 , except for $\log U .{ }^{3}$ Coefficient multiplied by $100 .{ }^{4}$ Calculated as $\_/ \beta .{ }^{5} \Delta \log \left(p_{k}-w\right) .{ }^{6} U$ rather than $\log U .{ }^{7} \Delta U$ rather than $\log U .{ }^{8} \Delta \log U$ rather than $\log U$ and actual rather than fitted value for $\Delta(\mathrm{k}-\mathrm{em})_{-1}$; also include an intercept dummy to capture the effects of exceptionally high wage increases in 1975 and 1982. ${ }^{9}$ Actual rather than fitted value for $\Delta(k-e m)_{-1}$; also includes $\Delta \log \left(p_{k}-w\right)$ with a coefficient of $-1.03(3.8)$. ${ }^{10} \mathrm{U}$ only significant after 1981. 


\section{Bibliography}

Andersen, P S (1999): "Alternative measures of real interest rates". Working Paper, Institute of Economics, University of Aarhus, forthcoming.

Blanchard, O J (1997): “The Medium Run”. Brookings Papers on Economic Activity, No. 2, pp. 89-158.

Browne, L E and R Hellerstein (1997): “Are we investing too little?” Federal Reserve Bank of Boston, New England Economic Review, November/December, pp. 29-50.

Bruno, M and J Sachs (1985): The Economics of Worldwide Stagflation. Oxford: Basil Blackwell.

Caballero, R J and M L Hammour (1998): "Jobless growth: appropriability, factor substitution and unemployment". Carnegie-Rochester Conference Series on Public Policy, pp. 51-94.

Cohen, D, K Hassett and J Kennedy (1995): "Are US investment and capitals at optimal levels?" Finance and Economics Discussion Series, No. 171, Federal Reserve Board.

Freedman, C and T Macklem (1998): “A comment on 'the great Canadian slump' ”. Canadian Journal of Economics, pp. 646-65.

Kirova, M S and R Lipsey (1997): "Does the United States invest 'too little'?” Federal Reserve Bank of St. Louis, Working Paper, No. 97-020A.

Nickell, S J (1998): “Unemployment: questions and some answers”. Economic Journal, pp. 802-16.

Phelps, E S (1994): Structural Slumps. Harvard University Press.

Poterba, J M (1997): "The rate of return to corporate capital and factor shares: new estimates using revised national income accounts and capital stock date". NBER, Working paper No. 6263. 




\section{Recent BIS Working Papers}

No.

49

September 1997

50

November 1997

51

November 1997

52

January 1998

53

March 1998

54

June 1998

55

June 1998

56

June 1998

57

July 1998

58

November 1998

59

November 1998

60

November 1998

61

November 1998

62

March 1999

63

March 1999

64

March 1999
Title

Why does the yield curve predict economic activity?

Dissecting the evidence for Germany and the United States

The euro and the dollar

Forecast errors and financial developments

Inflation and disinflation in Iceland

Exchange rate regimes and inflation and output in

Sub-Saharan countries

The coming transformation of continental European banking?

Spread overreaction in international bond markets

Commercial banks in the securities business: a review

One-step prediction of financial time-series

The importance of bank seniority for relationship lending

Portfolio selection using fuzzy decision theory

Output gap uncertainty: does it matter for the Taylor rule?

Foreign direct investment and employment in the industrial countries

The pricing of bank lending and borrowing: evidence from the federal funds market

Microeconomic inventory adjustment and aggregate dynamics

Precarious credit equilibria: reflections on the Asian financial crisis
Author

Frank Smets and Kostas Tsatsaronis

Robert N McCauley

Palle S Andersen

Palle S Andersen and Már Guðmundsson

Marc Klau

William R White

Gregory D Sutton

João A C Santos

Srichander

Ramaswamy

Stanley D Longhofer and João A C Santos

Srichander

Ramaswamy

Frank Smets

P S Andersen and $\mathrm{P}$ Hainaut

Craig H Furfine

Jonathan McCarthy and Egon Zakrajšek

Joseph Bisignano 


ISSN 1020-0959 